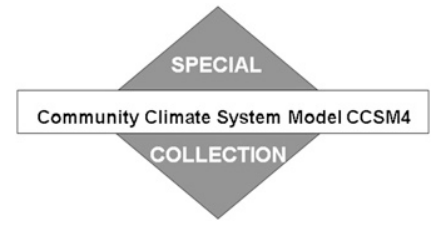

\title{
Simulating the Biogeochemical and Biogeophysical Impacts of Transient Land Cover Change and Wood Harvest in the Community Climate System Model (CCSM4) from 1850 to 2100
}

\author{
PETER J. LAWRENCE \\ National Center for Atmospheric Research, ${ }^{*}$ Boulder, Colorado \\ JOHANNES J. FEDDEMA \\ Department of Geography, University of Kansas, Lawrence, Kansas \\ Gordon B. Bonan, Gerald A. Meehl, Brian C. O’Neill, Keith W. Oleson, Samuel Levis, \\ DAVID M. LAWRENCE, ERIK KLUZEK, AND KeITH LindSAY \\ National Center for Atmospheric Research,* Boulder, Colorado \\ PETER E. THORNTON \\ Environmental Sciences Division, Oak Ridge National Laboratory, Oak Ridge, Tennessee
}

(Manuscript received 10 May 2011, in final form 25 October 2011)

\begin{abstract}
To assess the climate impacts of historical and projected land cover change in the Community Climate System Model, version 4 (CCSM4), new time series of transient Community Land Model, version 4 (CLM4) plant functional type (PFT) and wood harvest parameters have been developed. The new parameters capture the dynamics of the Coupled Model Intercomparison Project phase 5 (CMIP5) land cover change and wood harvest trajectories for the historical period from 1850 to 2005 and for the four representative concentration pathway (RCP) scenarios from 2006 to 2100. Analysis of the biogeochemical impacts of land cover change in CCSM4 reveals that the model produced a historical cumulative land use flux of $127.7 \mathrm{PgC}$ from 1850 to 2005, which is in general agreement with other global estimates of $156 \mathrm{PgC}$ for the same period. The biogeophysical impacts of the transient land cover change parameters were cooling of the near-surface atmosphere over land by $-0.1^{\circ} \mathrm{C}$, through increased surface albedo and reduced shortwave radiation absorption. When combined with other transient climate forcings, the higher albedo from land cover change was counteracted by decreasing snow albedo from black carbon deposition and high-latitude warming. The future CCSM4 RCP simulations showed that the CLM4 transient PFT parameters can be used to represent a wide range of land cover change scenarios. In the reforestation scenario of RCP 4.5, CCSM4 simulated a drawdown of 67.3 $\mathrm{PgC}$ from the atmosphere into the terrestrial ecosystem and product pools. By contrast the RCP 8.5 scenario with deforestation and high wood harvest resulted in the release of $30.3 \mathrm{PgC}$ currently stored in the ecosystem.
\end{abstract}

\footnotetext{
* The National Center for Atmospheric Research is sponsored by the National Science Foundation.
}

Corresponding author address: Peter J. Lawrence, NCAR, P.O. Box 3000, Boulder, CO 80307-3000.

E-mail: lawrence@ucar.edu

\section{Introduction}

Recent studies have shown that historical human land use and land cover change have significantly impacted the earth's climate through changes in the carbon cycle, through altered biogeochemical processes (Houghton 2003; Canadell et al. 2007; Bonan 2008; Shevliakova 
et al. 2009) and through changes in energy and moisture fluxes to the atmosphere, by altering biogeophysical processes (Betts et al. 2001; Feddema et al. 2005; Findell et al. 2007; Bala et al. 2007; Lawrence and Chase 2010). To address these climate impacts, the Coupled Model Intercomparison Project phase 5 (CMIP5) protocol prescribes historical and projected time series of land cover change and wood harvest that are internally consistent with emissions scenarios and development pathways that will guide the next Intergovernmental Panel on Climate Change (IPCC) assessment report [the Fifth Assessment Report (AR5)] (Taylor et al. 2009).

The new CMIP5 land cover change scenarios include land cover transformations and wood harvest that are based on detailed information about natural land cover distributions, anthropogenic land cover transformations and land use, and the carbon releases associated with these activities. These time series are represented through annual historical land cover change and wood harvest from 1850 to 2005 (Hurtt et al. 2006) and through four different representative concentration pathway (RCP) scenarios for future land cover change and wood harvest from 2006 to 2100 (van Vuuren et al. 2007; Wise et al. 2009; Fujino et al. 2006; Riahi et al. 2007).

For the CMIP5 climate modeling experiments, the National Center for Atmospheric Research (NCAR) is using the Community Climate System Model, version 4 (CCSM4) global climate model (Gent et al. 2011) as the primary climate model for physical climate simulations. To address the land cover and land use components of the CMIP5 protocol, CCSM4 has been developed to include annual transient land cover change in plant functional types (PFTs) and wood harvest of tree PFTs through new functionality in the Community Land Model (CLM4), as described in Lawrence et al. (2012) and Oleson et al. (2010).

To ensure consistency with the CMIP5 protocol, new annual CLM4-compatible PFT land cover change and tree PFT wood harvest parameters have been derived from the CMIP5 land cover change and wood harvest database from 1850 to 2100 . The annual values of the CMIP5 time series are combined with the CLM4 current day PFT parameters derived from Moderate Resolution Imaging Spectroradiometer (MODIS) satellite observations (Lawrence and Chase 2007) and with the CLM4 potential vegetation PFT parameters derived from bioclimatically reconstructed vegetation (Lawrence and Chase 2010). The resulting integrated parameters reflect the CMIP5 trajectories while maintaining the specific land surface PFT descriptions used in CLM4.

To assess how these new time series of CLM4 parameters impact the biogeochemical and biogeophysical processes in transient CCSM4 experiments, this paper
1) describes the processes by which the time series of CMIP5 land use and land cover change have been represented in CLM4 land surface parameters for both historical and projected scenarios; 2) evaluates the CLM4 parameters against the historical and projected times series in the context of the narrative of each CMIP5 scenario; 3) investigates the biogeochemical impacts of land use and land cover change in the CCSM4 1850 2005 historical and 2006-2100 projected transient climate experiments; and 4) investigates the historical biogeophysical impacts of land use and land cover change in the absence of and in combination with other climate forcing, such as increased atmospheric $\mathrm{CO}_{2}$, increased deposition of airborne sources of nitrogen, increased aerosols, and other sources of transient climate change.

\section{Data and methods}

\section{a. CMIP5 specified annual land cover change and wood harvest}

The CMIP5 experimental design protocol specifies transient land cover change and wood harvest for the historical 1850-2005 period and for all of the 2006-2100 RCP scenarios (Taylor et al. 2009). To meet this requirement historical land use and land cover change has been derived using the global land model (GLM) of Hurtt et al. (2006) based on the historical crop and pasture maps of the History Database of the Global Environment, version 3.0 (HYDE 3.0) database combined with historical national estimates of wood harvest and shifting cultivation. For the future RCP periods land use and land cover change have been individually estimated by four different integrated assessment modeling (IAM) groups, ensuring consistency with the emissions and development pathways of the RCPs. The time series are represented through annual global maps of land cover change and wood harvest on a $0.5^{\circ}$ grid. An overview of the historical and RCP time series specifications can be found in van Vuuren et al. (2011), with a summary for each time series shown in Table 1.

So that the individually derived time series can be used consistently in all of the modeling studies with a smooth transition between the historical and RCP periods, a harmonization process was developed by Hurtt et al. (2011) to convert all of the time series into a consistent series of land use transitions with the associated wood harvest for the period 1850-2100. The harmonization process integrates multiple data sources from the historical and future time series for the year 2005 to minimize differences in land cover area and carbon fluxes at the transition year while preserving the future changes at both aggregate and $0.5^{\circ}$ grid levels. The 


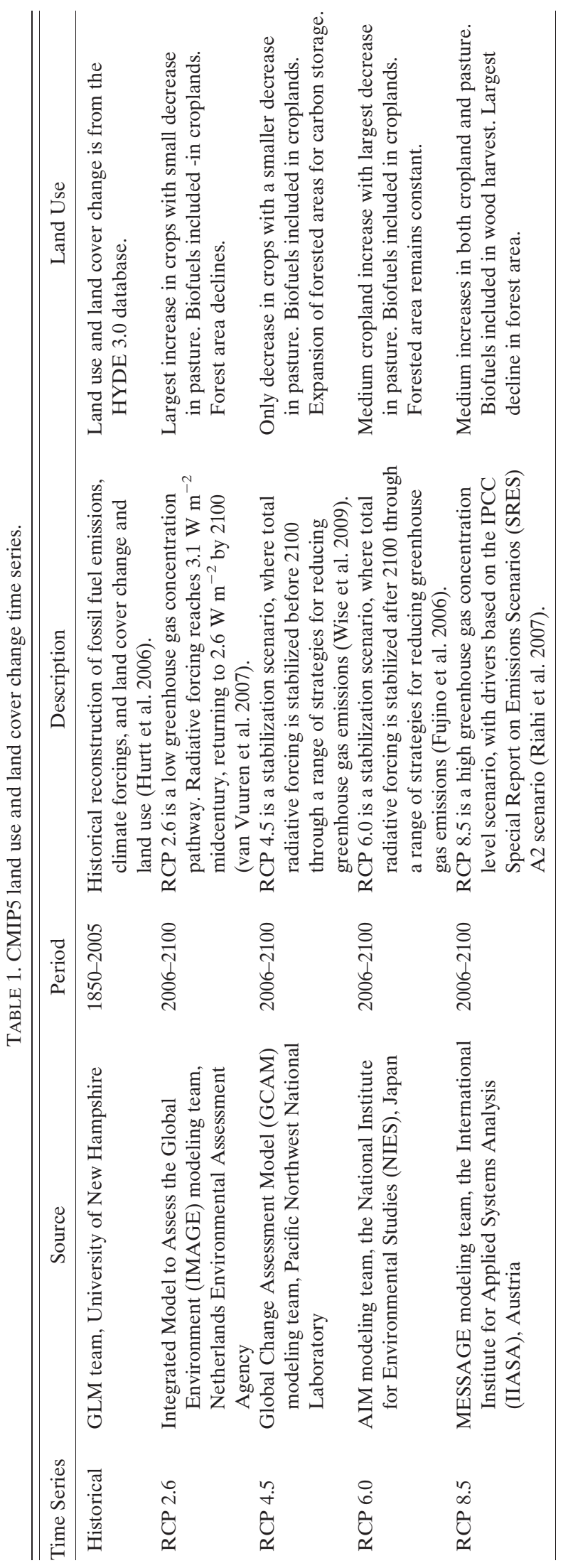

harmonized land use transitions were based around the four simplified land classes of primary vegetation (undisturbed natural vegetation), secondary vegetation (regrowth vegetation following human disturbance or a period of alternative land use), crop, and pasture.

Harmonized prescriptions of CMIP5 wood harvest statistics also are provided by Hurtt et al. (2011) for the historical and RCP time series. The wood harvest is prescribed spatially on the same $0.5^{\circ}$ grid as the land use class transitions for each year. To ensure consistency with the land use classes and the wood products generated, wood harvest is prescribed as both the area of land harvested and the amount of carbon extracted in the grid cell for a particular year. To account for the differences in standing amount of wood carbon as well as the differences in harvest intensity associated with the different land units, the harvest area and carbon amounts are prescribed for the five classes of primary forest, primary nonforest, secondary mature forest, secondary young forest, and secondary nonforest.

Discussions following the initial analysis of CCSM4 land cover change experiments found there were very high wood harvest areas compared to wood harvest carbon in the RCP 6.0 and RCP 8.5 time series (Chini et al. 2011, teleconference communication). The high wood harvest areas were traced to using gridded spatially explicit wood harvest targets from the Model for Energy Supply Strategy Alternatives and their General Environmental Impact (MESSAGE) and AIM groups for these two time series, rather than using regional targets with spatial downscaling in the GLM as done with the other three time periods (Hurtt et al. 2011). As a result of these discussions, new amended wood harvest targets were generated with regional targets through the GLM for the RCP 6.0 and RCP 8.5 time series (Chini et al. 2011). These new wood harvest parameters are used for the RCP 6.0 and RCP 8.5 CCSM4 simulations documented in this paper. The implications of the original wood harvest parameters on simulations in the CMIP5 CCSM4 modeling database are detailed further in the discussion.

The land use descriptions of the different time series in Table 1 reflect the range of human management actions that the IAM groups prescribed on vegetation in the future scenarios. The differences in these management pathways are shown through cumulative annual global changes in land unit area, along with cumulative global harvest area and carbon amount harvested in Table 2 for the RCP time series as well as the historical time series. As might be expected, the tables show that from 1850 to 2005 the historical time series had a large decrease in primary land, which was transformed into pasture, secondary land, and cropping, with the largest 
TABLE 2. CMIP5 GLM global total land cover change area for each land unit $\left(10^{6} \mathrm{~km}^{2}\right)$, cumulative global wood harvest area $\left(10^{6} \mathrm{~km}{ }^{2}\right)$, and cumulative global carbon harvest amount (Pg C) for the historical and RCP time series. RCP time series are from 2006 to 2100.

\begin{tabular}{lccrrrr}
\hline \hline \multicolumn{1}{c}{ Time series } & Primary & Secondary & Crop & Pasture & Harvest area & Harvest carbon \\
\hline Historical 1850-2005 & -48.98 & 13.71 & 9.81 & 25.47 & 47.44 & 101.53 \\
RCP 2.6 image & -15.27 & 10.66 & 5.29 & -0.67 & 140.65 & 164.59 \\
RCP 4.5 GCAM & -12.05 & 20.71 & -4.15 & -4.52 & 218.87 & 179.61 \\
RCP 6.0 AIM & -15.13 & 26.87 & 3.70 & -15.42 & 154.96 & 182.69 \\
RCP 8.5 MESSAGE & -24.51 & 18.30 & 2.77 & 3.44 & 214.63 & 248.24 \\
\hline
\end{tabular}

transition into pasture and the smallest transition into crop. The total harvest area was similar in size to the loss of primary land; however, two-thirds of the wood harvest occurred on secondary land.

Of the RCPs, the RCP 4.5 time series had the largest use of land management as a carbon mitigation strategy, with the expansion of forests combined with reductions in the area of cropland and pasture, as well as the use of some crop areas for biofuel production. The RCP 6.0 time series had less use of land management for carbon mitigation. The RCP kept forest areas constant with a large reduction in pasture, but there was a medium increase in crop area with some of the crop areas used for biofuels. The RCP 2.6 time series had relatively little effective use of land management for carbon mitigation with decreases in forest area and the largest increase in crops. This was offset by a small decrease in pasture and the use of some crop areas for biofuel. The RCP 8.5 time series had the least effective use of land management for carbon mitigation with the largest loss of forest area combined with medium increases in crop and pasture. The only effective measure of carbon mitigation was through the use of wood harvest as biofuel.

\section{b. Integrating CMIP5 land cover change into CLM4 land surface parameters}

The most recent version of CLM4 represents the land surface as a hierarchy of subgrid types, including glacier, lake, wetland, urban, and vegetated land units, with the vegetated land unit further divided into a mosaic of plant function types (PFTs) (Oleson et al. 2010). To transform the CMIP5 land cover change and wood harvest time series into CLM4 parameters, the fractional composition of the primary vegetation, secondary vegetation, crop, and pasture land units need to be faithfully represented for each grid cell and for each year of the time series in the PFT mosaics of CLM4. To achieve this each land unit is translated into fractional PFT values based on the current day (Lawrence and Chase 2007) and potential vegetation (Lawrence and Chase 2010) CLM4 land surface parameters of the grid cell. This translation is schematically shown in Fig. 1.
The methodology for creating the transient PFT dataset is based on four steps that are applied to every grid cell for each year of the time series. First, crop PFT composition is directly specified from the GLM crop land unit. In the Fig. 1 example, this is $25 \%$ for both the GLM land units and the CLM4 PFTs. Second, pasture PFTs are assigned based on grass PFTs found in the potential vegetation and year 2000 CLM4 land surface parameters scaled by the area of the GLM pasture land unit. In the example this is $25 \%$ in the land units that transform to $25 \% \mathrm{C} 4$ grass PFT. Third, primary PFTs are assigned from potential vegetation PFTs scaled by the GLM primary land unit. In the example the $20 \%$ primary land unit of year $N$ is divided into the primary PFTs shown based on the gridcell potential vegetation PFT composition.

Finally, secondary PFTs are assigned from the GLM secondary land unit based on the year 2000 secondary PFT composition. In the Fig. 1 example, the year 2000 secondary PFT composition is calculated using the year 2000 GLM land units and the year 2000 MODIS derived CLM4 PFTs, as the remaining PFTs once the year 2000 crop, pasture, and primary PFTs are removed. In the example, the calculated year 2000 secondary PFTs are used to divide the $30 \%$ of secondary unit into PFTs for the year. The individual PFT mosaics of each GLM land unit class are then aggregated to give a single PFT mosaic for the grid cell for that particular year, as shown at the end of Fig. 1.

One of the issues apparent in the CMIP5 time series is the ambiguous definition of the pasture land unit. The definition of pasture can be applied as a land cover where grasses are specifically grown for grazing purposes (e.g., for dairy herds that graze on grass fields), or simply as the human land use of grazing where herds opportunistically use any natural vegetation grown in an area (e.g., pastoral herding practices as used in Africa or Mongolia, or rangeland grazing in Australia).

The historical CMIP5 time series suggests that the pasture land unit applies to both of these definitions, as there are very intensive pasture values in very sparsely vegetated parts of the world that cannot be considered equivalent to the intensive grazing of the lush pastoral 
Schematic of Transformation from Land Units to PFTs for a grid cell in Year $\mathbf{N}$

RCP Land Units for Year $N$

\begin{tabular}{|c|c|}
\hline \multicolumn{2}{|c|}{ Primary (V) } \\
\hline क & Crop (C) \\
\hline ভ্ষ & Pasture (P) \\
\hline
\end{tabular}

Describe Land Units in PFTs from CLM 4.0 PFTs

\begin{tabular}{|c|c|}
\hline \multicolumn{2}{|c|}{ Potential Vegetation PFTs } \\
\hline 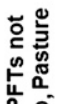 & $\begin{array}{l}\text { Current Day Crop } \\
\text { PFTs }\end{array}$ \\
\hline 突 & $\begin{array}{l}\text { Current Day } \\
\text { Herbaceous PFTs }\end{array}$ \\
\hline
\end{tabular}

Example Transformation from Land Units to PFTs with wood harvest for a grid cell in Year $\mathrm{N}$

1. GLM Year N Land Units
\begin{tabular}{|lll|}
\hline Primary $-20 \%$ & Primary Harvest $\quad-1 \%$ \\
Secondary $-30 \%$ & Secondary Harvest $-2 \%$ \\
Crop $-25 \%$ & \\
Pasture $-25 \%$ & \\
\hline
\end{tabular}

2.CLM4 Year N Land Unit Component PFTs

\begin{tabular}{|c|c|c|}
\hline Primary & $\begin{array}{l}\text { - Tropical Broadleaf Evergreen - } \\
\text { - Tropical Broadleaf Deciduous - } \\
\text { - C4 Grass } \\
\text { - Bare Soil } \\
\text { - Tree Harvest }\end{array}$ & $\begin{array}{r}-\quad 13 \% \\
-\quad 4 \% \\
-\quad 2 \% \\
-\quad 1 \% \\
-0.85 \%\end{array}$ \\
\hline Second & $\begin{array}{l}\text { - Tropical Broadleaf Evergreen - } \\
\text { - Tropical Broadleaf Deciduous - } \\
\text { - C4 Grass } \\
\text { - Bare Soil } \\
\text { - Tree Harvest }\end{array}$ & $\begin{array}{l}-5.25 \% \\
-\quad 12 \% \\
-\quad 7.5 \% \\
-5.25 \% \\
-1.15 \%\end{array}$ \\
\hline $\begin{array}{l}\text { Crop } \\
\text { Pasture }\end{array}$ & $\begin{array}{l}\text { - Crop } \\
\text { - C4 Grass }\end{array}$ & $\begin{array}{l}-\quad 25 \% \\
-\quad 25 \%\end{array}$ \\
\hline
\end{tabular}

3.CLM4 Year N Final Aggregated PFTs

\begin{tabular}{|c|c|}
\hline $\begin{array}{l}\text { Tropical Broadleaf Evergreen Tree } \\
\text { Tropical Broadleaf Deciduous Tree } \\
\text { Crop } \\
\text { C4 Grass } \\
\text { Bare Soil } \\
\text { Tree Harvest }\end{array}$ & $\begin{array}{rr}-18.25 \% \\
. \quad 16 \% \\
-\quad 25 \% \\
-\quad 34.5 \% \\
-\quad 6.25 \% \\
-\quad 2 \%\end{array}$ \\
\hline
\end{tabular}

GLM Year 2000 Land Units

\begin{tabular}{|ll}
\hline Primary & $-10 \%$ \\
Secondary & $-20 \%$ \\
Crop & $-40 \%$ \\
Pasture & $-30 \%$
\end{tabular}

CLM4 Year 2000 MODIS derived PFTs

\begin{tabular}{|ll|}
\hline Tropical Broadleaf Evergreen Tree & $-10 \%$ \\
Tropical Broadleaf Deciduous Tree & $-10 \%$ \\
Crop & $-40 \%$ \\
C4 Grass & $-36 \%$ \\
Bare Soil & $-4 \%$
\end{tabular}

CLM4 Potential Veg PFTs

Tropical Broadleaf Evergreen Tree $\quad-65 \%$ Tropical Broadleaf Deciduous Tree - $20 \%$ C4 Grass $\quad-10 \%$ Bare Soil $\quad-5 \%$

CLM4 Year 2000 calculated Secondary PFTs

Tropical Broadleaf Evergreen Tree $\quad 3.5 \%$ Tropical Broadleaf Deciduous Tree - $8 \%$ C4 Grass $\quad 5 \%$ Bare Soil $3.5 \%$

FIG. 1. Schematic and example of translation of CMIP5 historical and RCP land cover change time series from the GLM primary, secondary, crop, and pasture land units and wood harvest to CLM4 PFT and tree harvest parameters. All percentages are of the grid cell.

grass fields of Europe or North America. To address these definitional concerns for the pasture land unit, the density of grass PFTs in the pasture fraction was limited by the maximum vegetation density of the grid cell based on the bare soil fraction of the current day and potential vegetation parameters.

The annual tree PFT harvest parameters also are calculated for CLM4 based on the harvest area of the CMIP5 time series combined with the transient tree PFT values calculated for the grid cell in the year of harvest. In the Fig. 1 example, the primary wood harvest area of $1 \%$ of the grid cell is transformed to a tree wood harvest of $0.85 \%$ of the grid cell, as the primary land unit composition has $85 \%$ tree PFTs from the potential vegetation. The secondary wood harvest of $2 \%$ of the grid cell, however, transforms to a tree wood harvest of $1.15 \%$ of the grid cell, as the secondary land unit composition has $57.5 \%$ tree PFTs.

As CLM4 has no explicit representation for primary or secondary forest or for different harvest prescriptions, the harvest values are applied directly to the mean standing carbon in the tree PFTs. This representation has the potential to misrepresent the amount of carbon standing in the primary or secondary trees, as it uses grid cell average carbon values for the tree PFT rather than explicit representations for the two land units. To ensure smooth transitions within CLM4, PFT transitions and wood harvest are performed at the time step of the model using linear interpolation between the closest annual parameter values found in the time series. 


\section{c. Experimental design for sensitivity of CCSM4 climate to land cover change}

As the basis for our investigation into the biogeochemical and biogeophysical impacts of transient land cover change in CCSM4, we analyzed the land surface biogeochemistry and climate of a single realization of the NCAR CMIP5 fully coupled CCSM4 experiments with all transient forcings and atmospheric forcings prescribed through concentrations rather than emissions at the $0.9^{\circ} \times 1.25^{\circ}$ finite volume resolution. In each climate simulation land surface biogeochemistry and biogeophysics were simulated using the CLM4 land surface model with the carbonnitrogen $(\mathrm{CN})$ option dynamically simulating plant growth, organic matter decay, soil carbon and nitrogen chemistry, land cover change, and wood harvest. The details of this model are fully described in Lawrence et al. (2012) and Oleson et al. (2010).

The CCSM4 historical transient experiment starts in 1850 from the end of a 2300-yr spinup control simulation and simulates climate under full transient forcings through prescribed changes in solar irradiance, greenhouse gases $\left(\mathrm{CO}_{2}, \mathrm{CH}_{4}, \mathrm{~N}_{2} \mathrm{O}, \mathrm{O}_{3}, \mathrm{CFCs}\right)$, natural and anthropogenic aerosol burden, and aerosol (black carbon and dust) and nitrogen deposition, as described in Gent et al. (2011). Each of the RCP climate simulations continued from the end of the historical simulation with the same set of RCP specific transient forcings, as detailed in Taylor et al. (2009).

The biogeochemical impacts of land use and land cover change in these simulations were evaluated through investigating changes in CLM4-CN carbon pools and fluxes, as shown in Fig. 2a. The biogeophysical impacts were evaluated through investigating changes in surface climate focusing on changes in the surface radiation and energy fluxes shown in Figs. $2 b$ and $2 c$. As our investigations were limited to the biogeochemical and biogeophysical response of the land surface, a full analysis of all changes in the global climate in these simulations was beyond the scope of this paper. For context, however, the global transient land climate forcing from each of these simulations is shown for land near-surface air temperature, prescribed atmospheric $\mathrm{CO}_{2}$ concentration, and airborne nitrogen deposition in Fig. 3.

To investigate the biogeophysical impacts of land cover change in the CCSM full transient simulations, it was necessary to assess which surface climate forcings were coming from land cover change and how those forcings combined with the other transient forcings to produce the climate impacts in the simulations. For this investigation we repeated the historical CCSM4 simulation as a land-cover-change-only experiment in which transient land cover change and wood harvest were prescribed but all other forcings remained at 1850 control experiment values. The changes in land surface fluxes and land surface climate over the single forcing experiment were then compared to the changes found in the full transient historical experiment to identify the climate impacts of historical land cover change in isolation from and in combination with all of the other historical forcing factors.

\section{Impacts of transient land cover change in CCSM4}

\section{a. Land cover change in CLM4 plant function types}

The new translation methods were used to generate annual CLM4 PFT parameters for each year of the historical and future RCP time series at the $0.5^{\circ}$ resolution of the GLM land unit output from the Hurtt et al. (2011) harmonization process. The total changes in PFT area and areas of tree PFT harvested are shown in Table 3 for each of the historical and RCP time series. The land cover change differences in the CLM4 PFT parameters are mapped globally in Fig. 4 for tree and grass PFTs and in Fig. 5 for crop PFTs and annual tree PFT harvest area. The global time series of annual tree, crop, and grass PFT area are shown in Fig. 6 along with annual tree PFT harvest area.

The historical total changes in PFTs show the direct allocation of crop land unit to crop PFT with the same increase of $9.8 \times 10^{6} \mathrm{~km}^{2}$ in both the CLM4 PFTs and the GLM land units (Tables 2 and 3). The historical parameters had a decrease in the area of tree PFTs of $-5.5 \times 10^{6} \mathrm{~km}^{2}$, which was almost twice the reduction in grass PFTs of $-3.3 \times 10^{6} \mathrm{~km}^{2}$. The total reduction in shrub PFTs of $-1.0 \times 10^{6} \mathrm{~km}^{2}$ was smaller than either tree or grass PFTs, reflecting the low shrub PFT density on primary land and the preference for arable lands with other natural PFTs for conversion to crop and pasture.

The decrease in the area of natural PFTs is substantially smaller than the historical decrease in the area of the GLM primary land unit (Tables 2 and 3), reflecting the large amounts of bare soil in the CLM4 PFT mosaic of sparsely vegetated primary land prior to conversion to secondary vegetation, crop, or pasture PFTs. The total global tree PFT harvest area of $18.5 \times 10^{6} \mathrm{~km}^{2}$ also is substantially lower than the GLM wood harvest area (Table 2). This reflects the very low tree densities found in nonforest areas, which are specified as harvested in the CMIP5 database.

The global historical land cover change maps (Figs. $4 \mathrm{a}, \mathrm{b}$ and $5 \mathrm{a}$ ) show that historical increases in cropping were sourced from both trees and grasses. Increases in 
(a) Analyzed CLM4 CN Carbon Pools and Fluxes

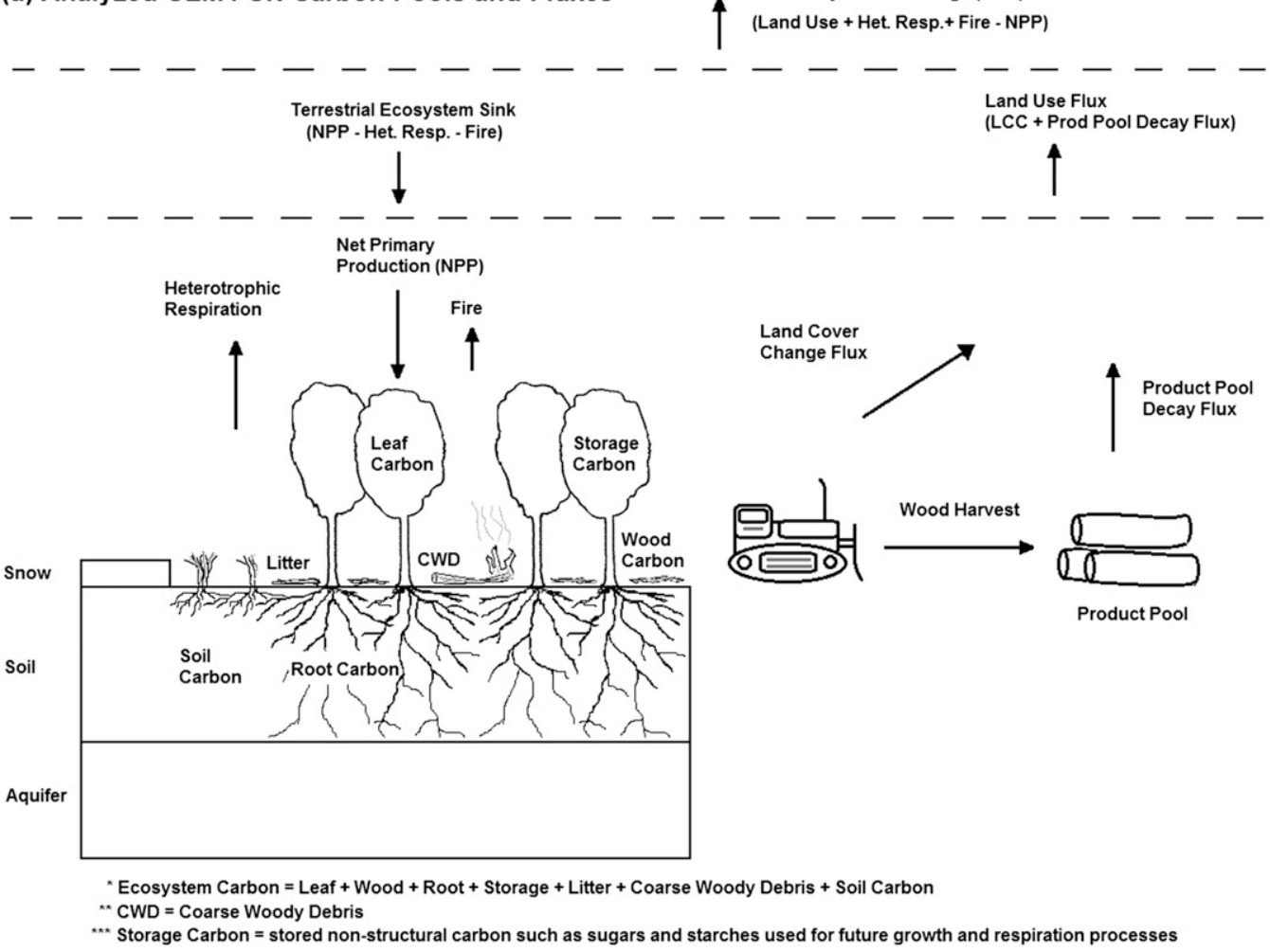

(b) Analyzed CLM4 Radiation Fluxes

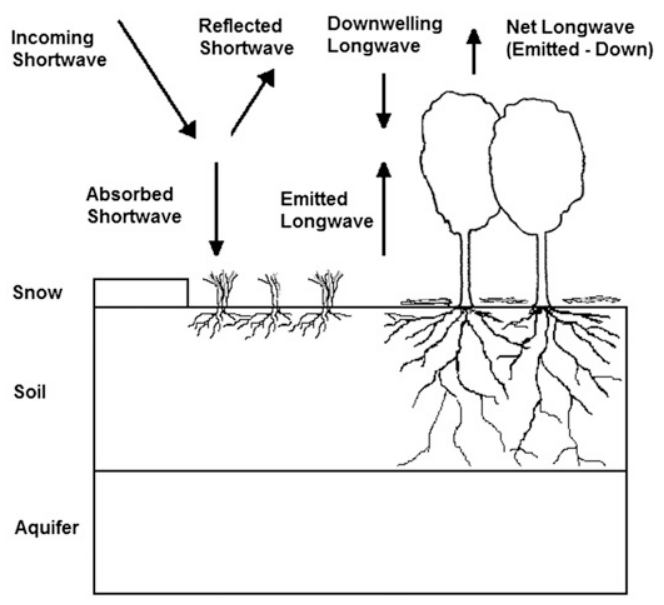

(c) Analyzed CLM4 Heat Fluxes

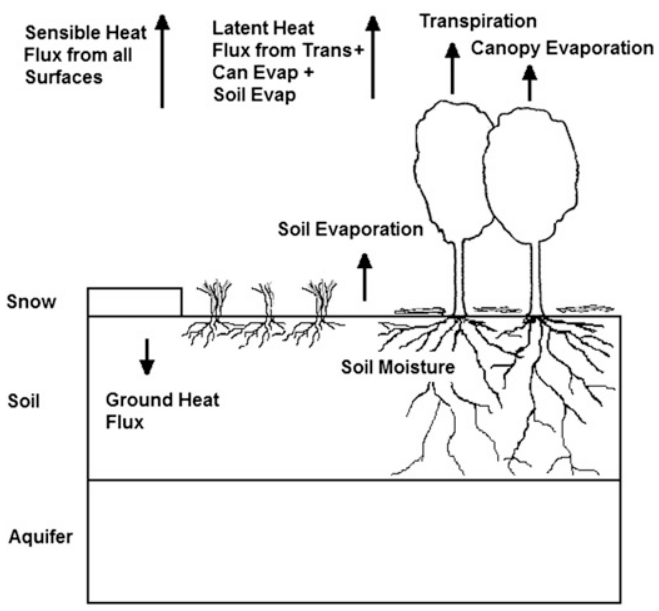

FIG. 2. Analyzed CLM4 biogeochemical pools and fluxes and biogeophysical surface radiation and heat fluxes. Arrow directions indicate sign convention of fluxes.

pasture however required retention or increases in grasses in many areas. This is reflected in the widespread decrease in trees, but the increases in grasses in eastern Europe, China, eastern North America, and eastern South America. The historical global time series plots (Fig. 6) show a relatively consistent decrease in tree and grass PFTs and increase in crop PFTs through the
1850-2005 period, reflecting the historical changes in GLM land units.

As shown with the GLM land units, the RCP 2.6 parameter time series has the largest increase in crop PFTs of all RCPs at $5.3 \times 10^{6} \mathrm{~km}^{2}$ (Table 3 ). The increase in cropping is associated with nearly equal decreases in tree PFTs at $-2.7 \times 10^{6} \mathrm{~km}^{2}$ and grass PFTs 
(a) CCSM 4.0 Global Averaged Land $2 \mathrm{~m}$ Air Temperature - 10 year smoothed

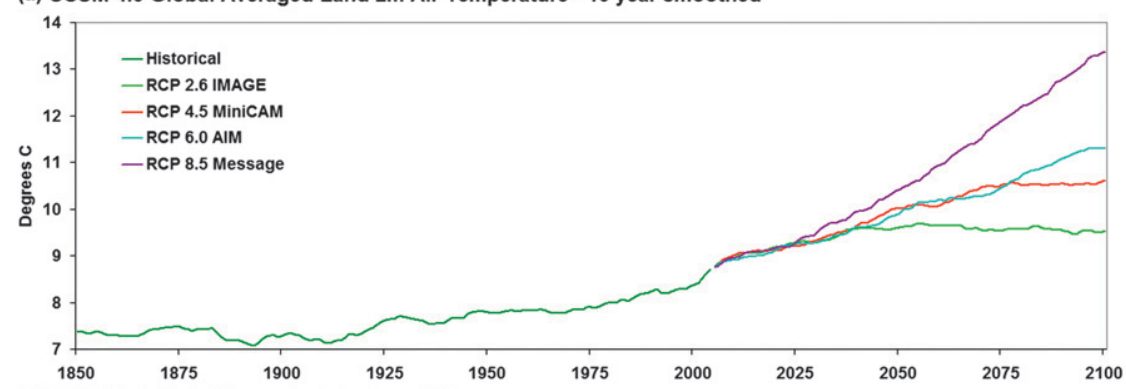

(b) CCSM 4.0 Global Prescribed Surface $\mathrm{CO} 2$

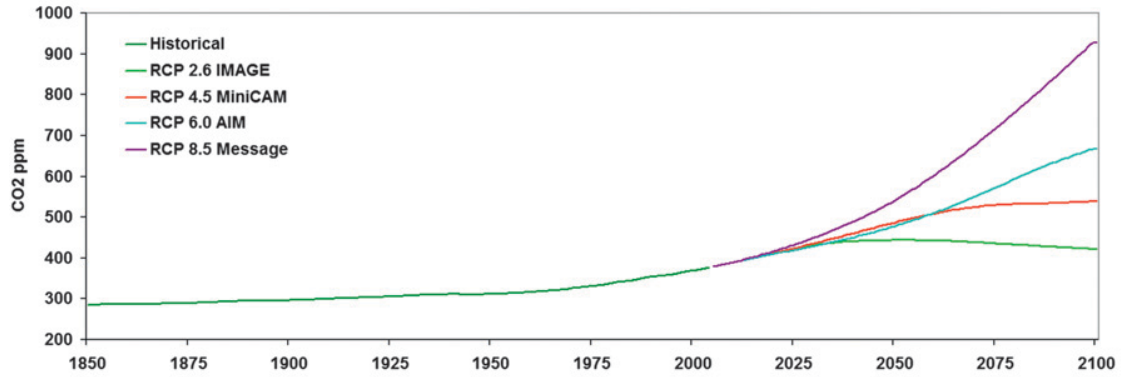

(c) CCSM 4.0 Global Total Airborne Nitrogen Deposition

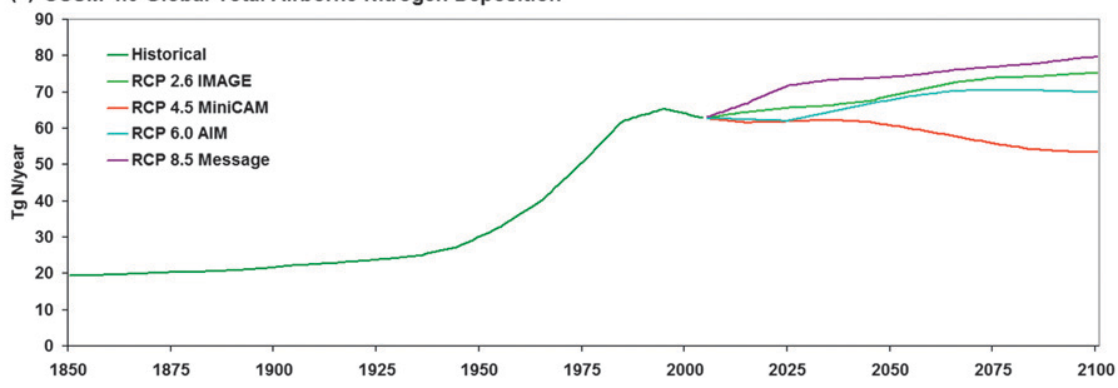

FIG. 3. CMIP5 global historical and RCP land surface forcings of near-surface land air temperature, atmospheric CO concentration, and nitrogen deposition from CCSM4 climate simulations.

at $-2.1 \times 10^{6} \mathrm{~km}^{2}$, and with a smaller decrease in shrub PFTs at $-0.4 \times 10^{6} \mathrm{~km}^{2}$. The total tree PFT harvest areas are the second highest of the RCPs at $88.2 \times$ $10^{6} \mathrm{~km}^{2}$. The harvest area is much lower than the GLM harvest area, reflecting the low tree PFT density found in nonforest harvest areas in the RCP.

The RCP 2.6 global PFT land cover change maps (Figs. 4c and 4d) show that the decreases in tree PFTs are larger in the Southern Hemisphere with widespread decreases in Africa, South America, and the tropical forests and savannas of Australia, following increases in cropping in these regions (Fig. 5c). Northern Hemisphere changes in tree PFTs are mixed with both increases and decreases, while the changes in grass PFTs closely mirror the changes in pasture. The global PFT time series plots (Fig. 6) show that RCP 2.6 is the most consistent in continuing the historical trends through to 2100 for all PFTs and for increases in tree PFT wood

TABLE 3. CMIP5 total area of global land use and land cover change over the historical and RCP time series in CLM4 PFT and tree PFT harvest parameters $\left(10^{6} \mathrm{~km}^{2}\right)$.

\begin{tabular}{lrrrrrrr}
\hline \hline \multicolumn{1}{c}{ Time series } & Trees & Shrubs & Crop & Grasses & Forest tree harvest & Nonforest tree harvest & All tree harvest \\
\hline Historical 1850-2005 & -5.53 & -0.97 & 9.81 & -3.25 & 16.49 & 1.98 & 18.47 \\
RCP 2.6 image & -2.68 & -0.41 & 5.29 & -2.10 & 59.72 & 28.47 & 88.18 \\
RCP 4.5 GCAM & 2.96 & 0.19 & -4.15 & 0.99 & 54.81 & 6.15 & 68.96 \\
RCP 6.0 AIM & -0.33 & -0.31 & 3.70 & -2.95 & 64.01 & 30.83 & 88.16 \\
RCP 8.5 MESSAGE & -3.51 & -0.10 & 2.77 & 0.85 & 92.40 & & 123.23 \\
\hline
\end{tabular}


(a) Historical (2005-1850) Tree PFTs $\%$

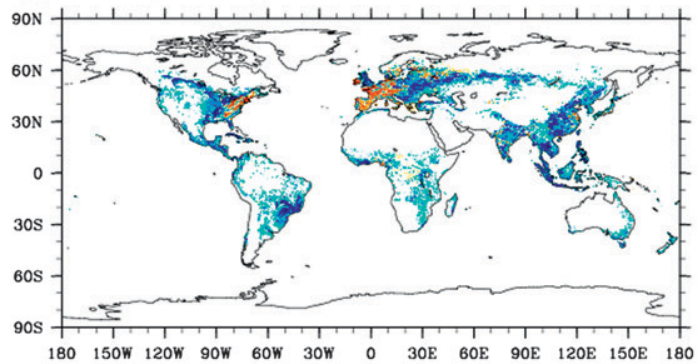

(b) Historical (2005-1850) Grass PFTs

(c) RCP 2.6 IMAGE (2100-2006) Tree PFTs

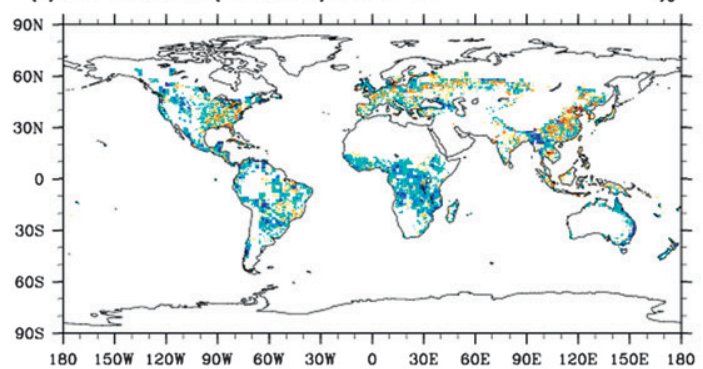
$\%$
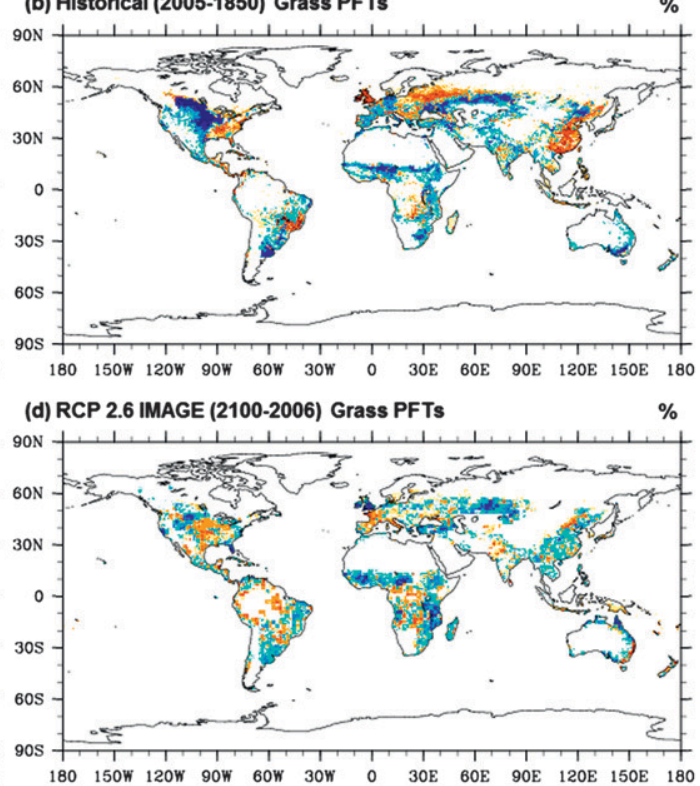

(e) RCP 4.5 MiniCAM (2100-2006) Tree PFTs

(f) RCP 4.5 MiniCAM (2100-2006) Grass PFTs \%
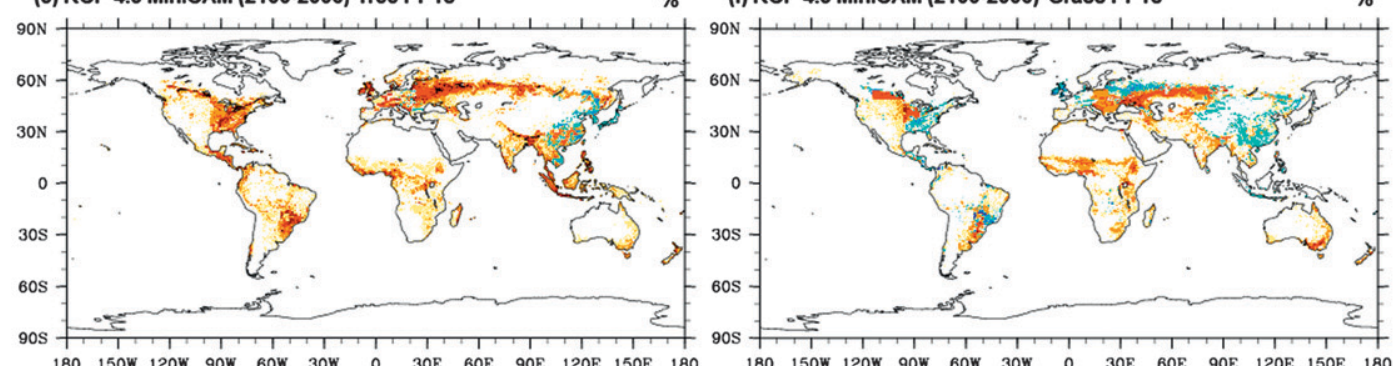

(g) RCP 6.0 AIM (2100-2006) Tree PFTs

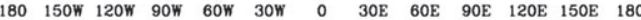

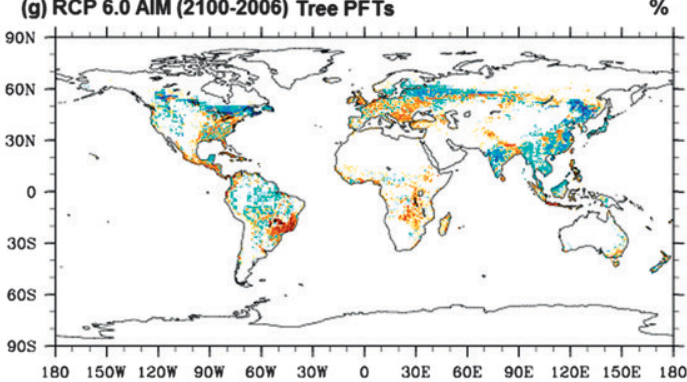

(h) RCP 6.0 AIM (2100-2006) Grass PFTs

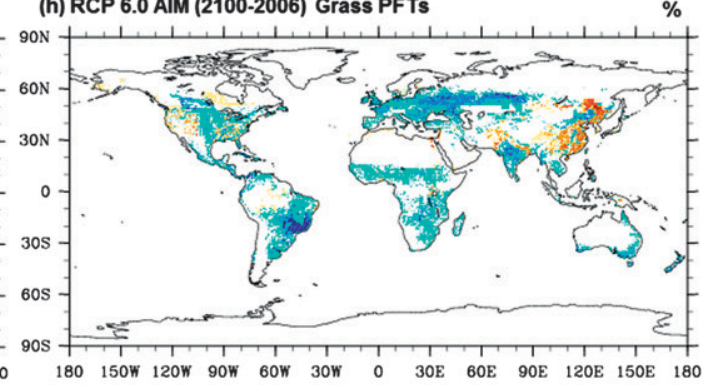

(i) RCP 8.5 Message (2100-2006) Tree PFTs

(j) RCP 8.5 Message (2100-2006) Grass PFTs
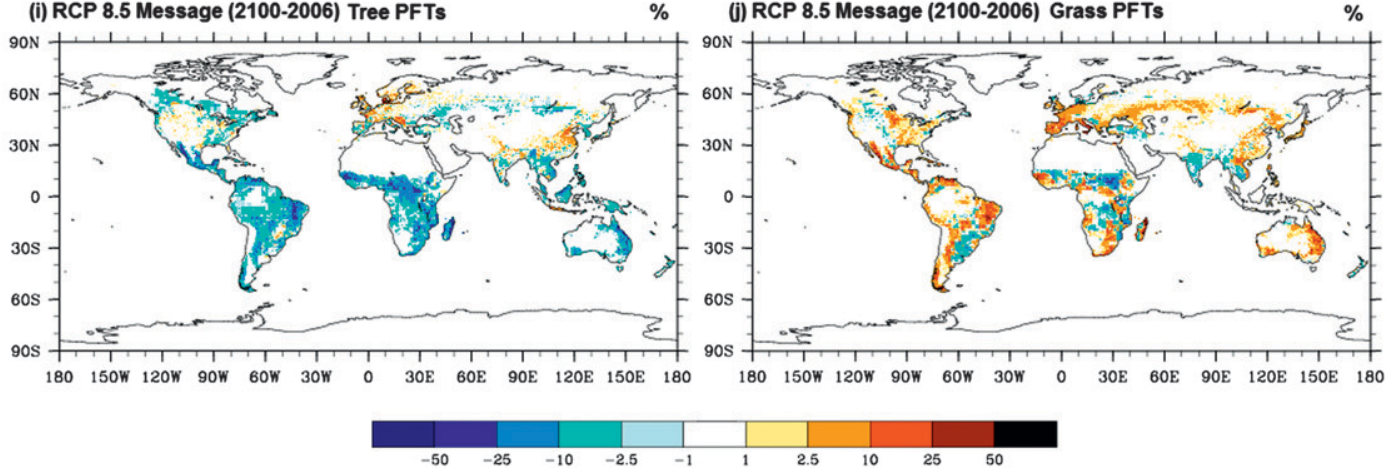

FIG. 4. Land cover change in CLM4 tree and grass plant function types (PFTs) for the CMIP5 historical (1850-2005) and RCP (2006-2100) periods. 
(a) Historical (2005-1850) Crop PFTs

$\% \quad$ (b) Historical (2005-1850) Tree PFT Harvest

$\%$
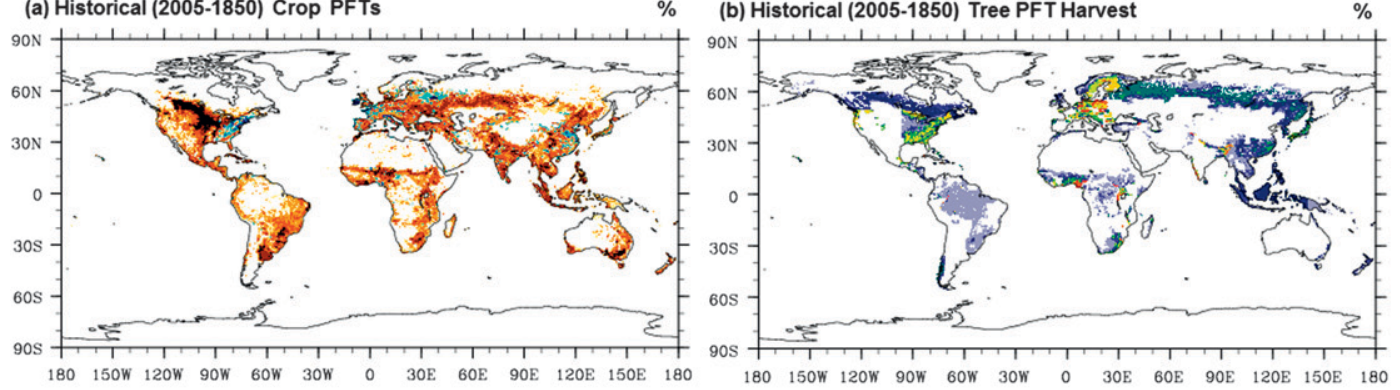

(c) RCP 2.6 IMAGE (2100-2006) Crop PFTs $\%$
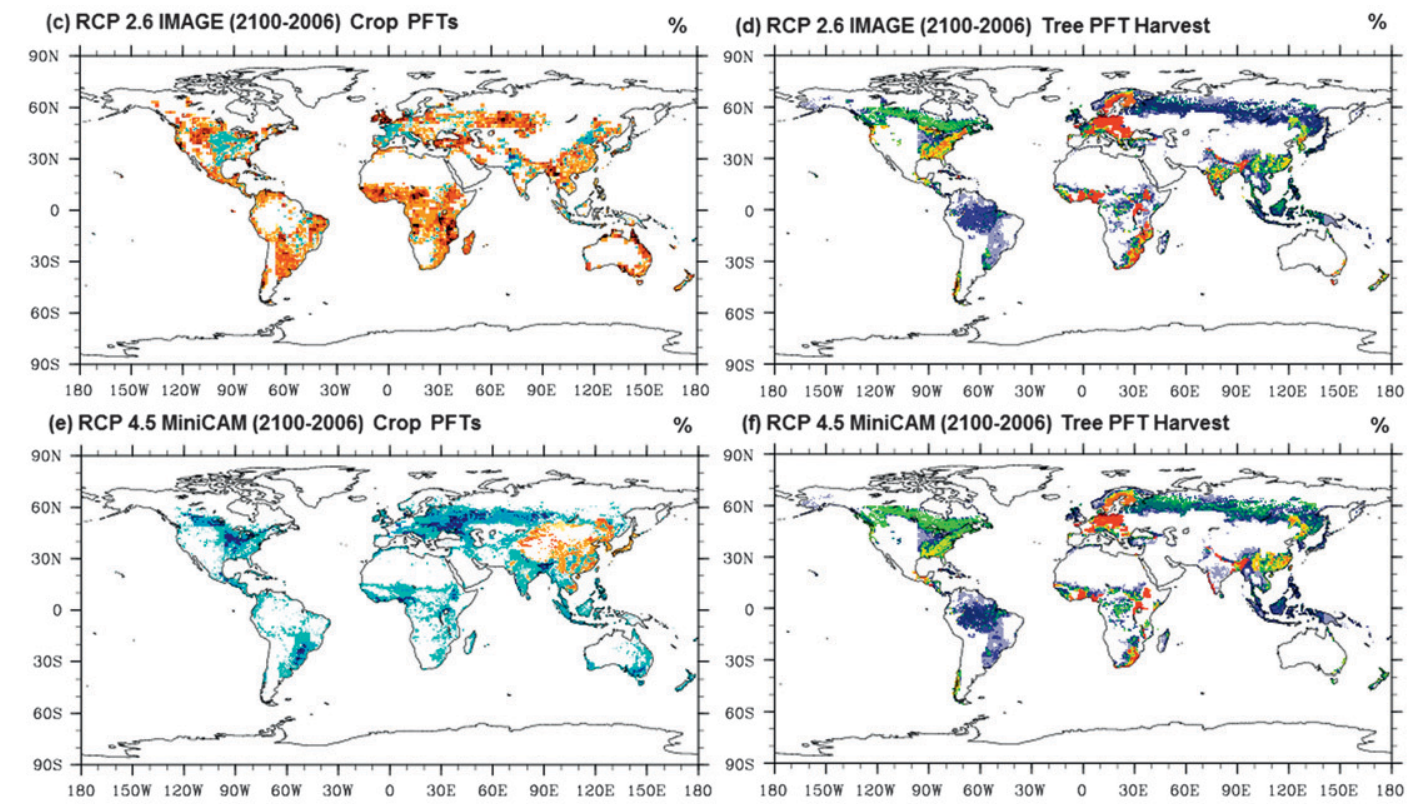

(f) RCP 4.5 MiniCAM (2100-2006) Tree PFT Harvest $\quad \%$
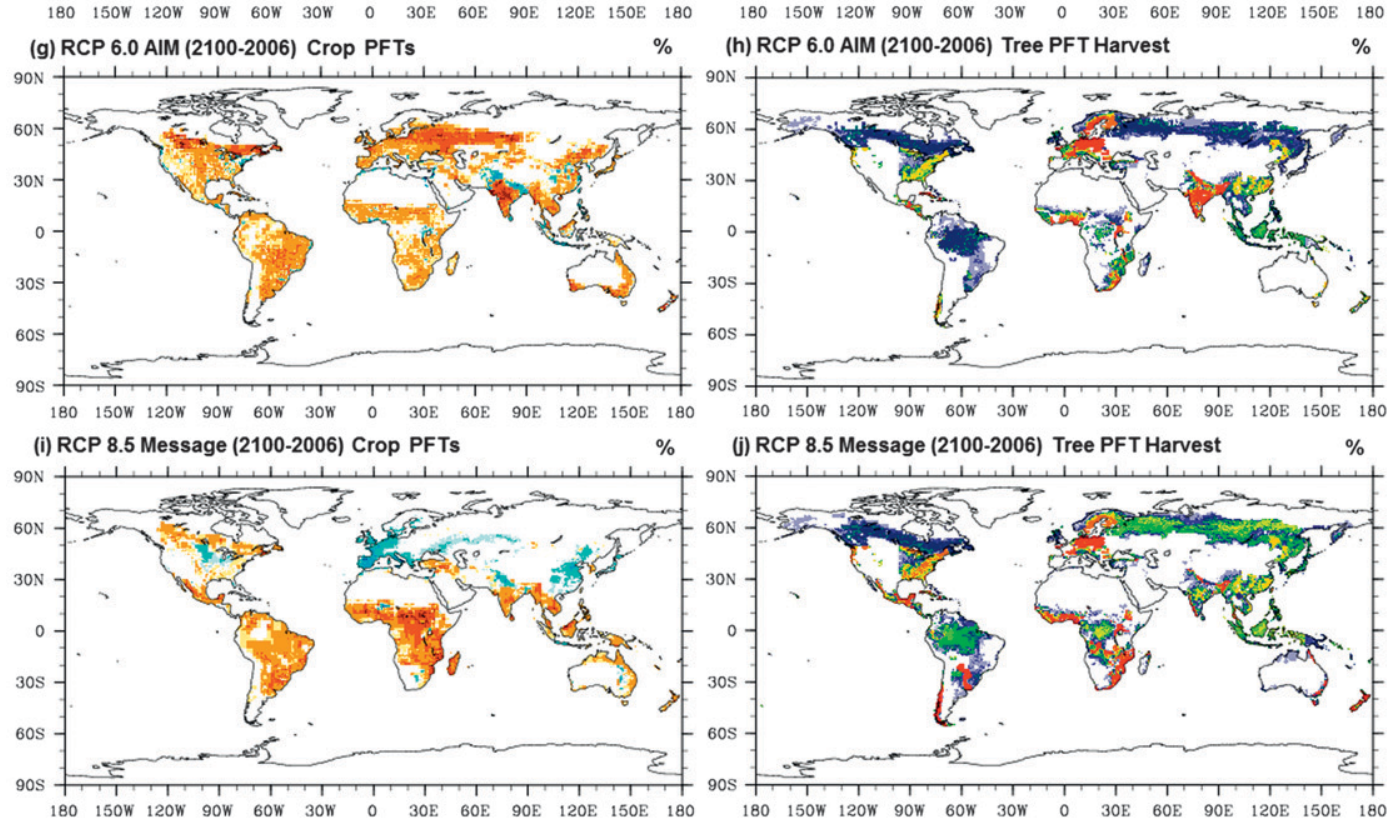

(h) RCP 6.0 AIM (2100-2006) Tree PFT Harvest

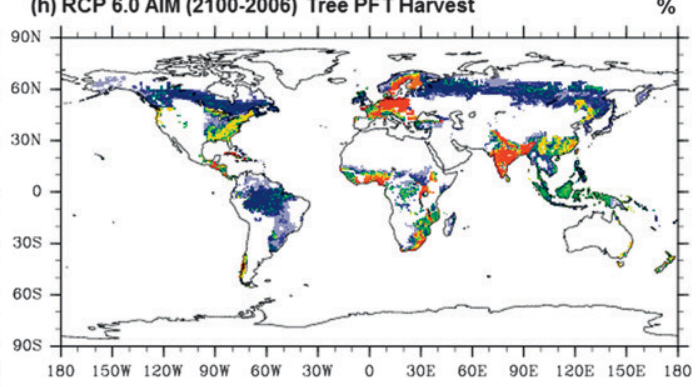

(i) RCP 8.5 Message (2100-2006) Tree PFT Harvest
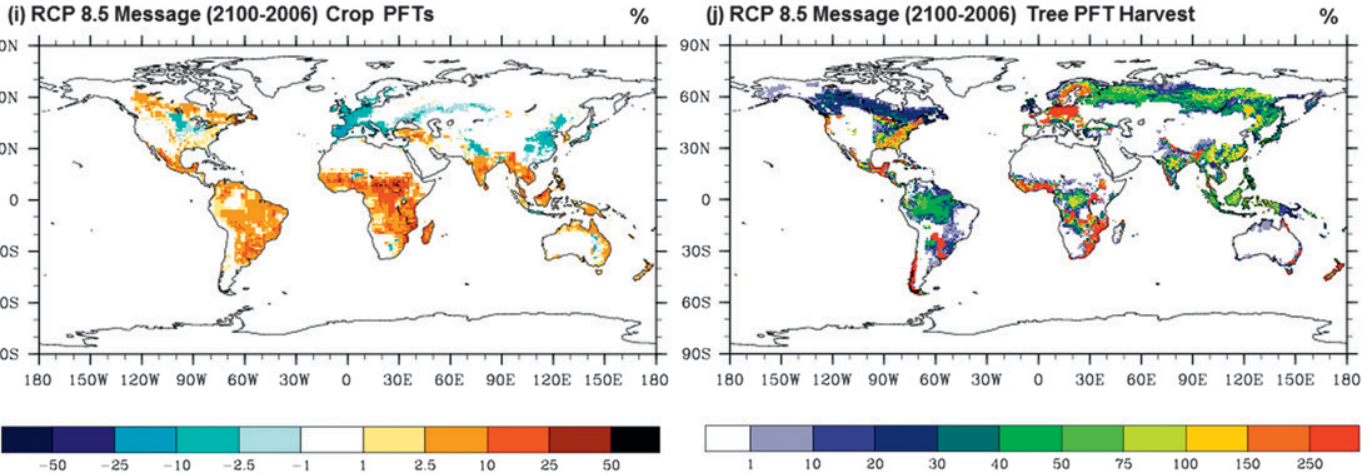

FIG. 5. Land cover change in CLM4 crop PFTs and percentage of tree PFTs harvested in CMIP5 historical and RCP periods. Harvest percentages over $100 \%$ indicate multiple harvests on the same tree areas within the period. 


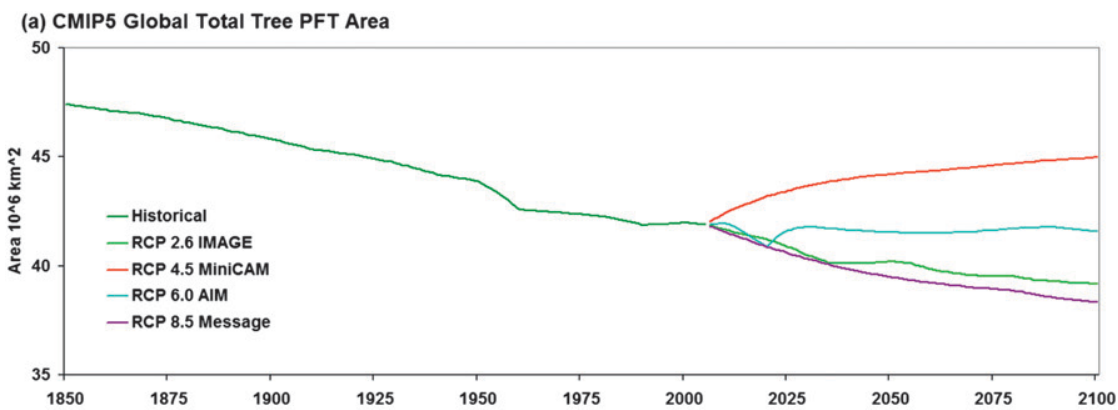

(b) CMIP5 Global Total Crop PFT Area

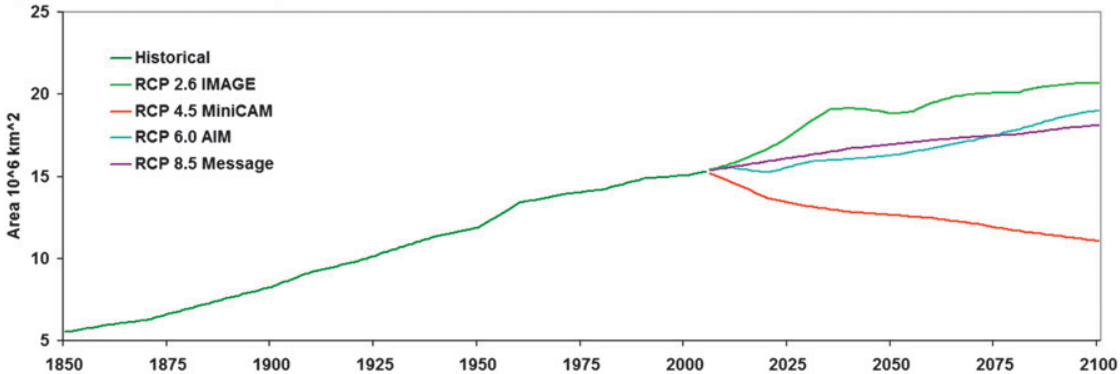

(c) CMIP5 Global Total Grass PFT Area

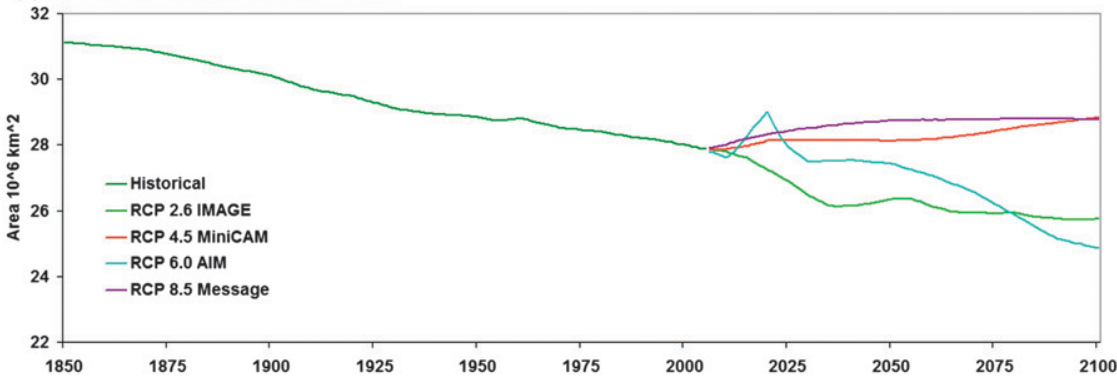

(d) CMIP5 Global Total Annual Tree PFT Harvest Area

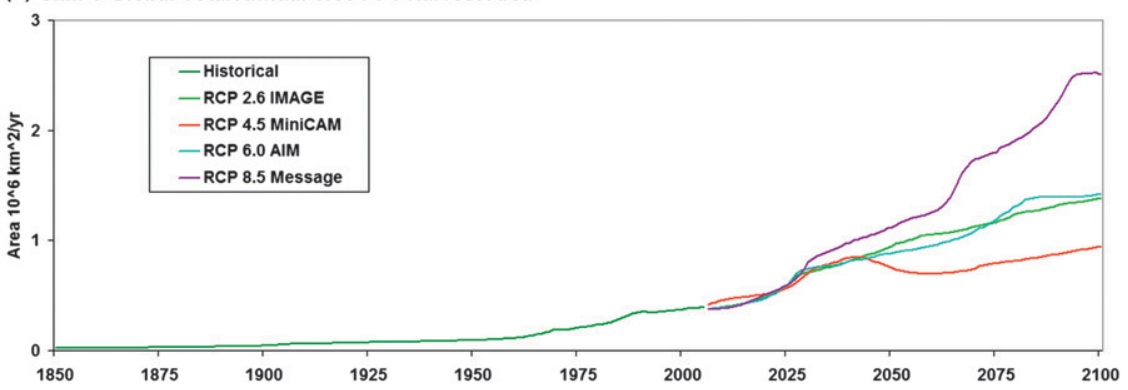

FIG. 6. CMIP5 global historical and RCP land cover change in land unit area and land use in wood harvest area in CLM4 PFT parameters.

harvest area. The other RCPs all diverge from historical trends to some extent for a group of PFTs or for tree PFT harvest area.

As in the GLM land units, the RCP 4.5 time series is the only RCP to have a reduction in crop PFT area at $-4.2 \times 10^{6} \mathrm{~km}^{2}$ (Table 3 ). The crop reduction results in the large increase in tree PFTs of $3 \times 10^{6} \mathrm{~km}^{2}$ and the smaller increases in grass PFTs of $1 \times 10^{6} \mathrm{~km}^{2}$. This reflected the forest area expansion of the RCP. Tree
PFT wood harvest is the lowest of the RCPs at $69 \times$ $10^{6} \mathrm{~km}^{2}$, which again is a third of the GLM harvest area value, reflecting the low PFT tree density in nonforest wood harvest areas. The RCP 4.5 global PFT land cover change maps (Figs. 4e and 4f) show that tree PFT increases follow decreases in crops (Fig. 5e); however, changes in grass PFTs are more complex, influenced by both changes in pasture and the potential and current vegetation that exist prior to and after land use. 
TABLE 4. CMIP5 historical and RCP time series global average annual carbon fluxes from CCSM4 full transient climate simulations $\left(\mathrm{PgC} \mathrm{yr}^{-1}\right) *$. Variables are net primary production (NPP); Land use; heterotrophic respiration (Het resp); fire; net ecosystem exchange (NEE); gross primary production (GPP); wood harvest; and sink from the atmosphere without land use (NPP - Het resp - Fire).

\begin{tabular}{|c|c|c|c|c|c|c|c|c|}
\hline Time series & NPP & Land use & Het resp & Fire & NEE & GPP & Harvest & Sink \\
\hline Historical 1850-2005 & 42.79 & 0.76 & 40.37 & 2.03 & 0.37 & 121.40 & 0.41 & 0.39 \\
\hline RCP 2.6 image & 48.00 & 1.84 & 44.34 & 2.05 & 0.18 & 138.32 & 1.43 & 1.61 \\
\hline RCP 4.5 GCAM & 49.25 & 1.56 & 44.65 & 2.40 & -0.69 & 142.85 & 1.52 & 2.20 \\
\hline RCP 6.0 AIM & 49.70 & 1.90 & 44.80 & 2.12 & -0.35 & 144.59 & 1.65 & 2.78 \\
\hline RCP 8.5 message & 51.11 & 2.70 & 46.63 & 2.24 & 0.38 & 151.31 & 2.54 & 2.25 \\
\hline
\end{tabular}

* Land use, heterotrophic respiration, fire, and NEE are all positive to the atmosphere. Wood harvest is positive out of the ecosystem into the product pools. All other fluxes are positive into the ecosystem.

The RCP 6.0 time series has the largest decrease in grass PFTs of all the RCPs at $-3 \times 10^{6} \mathrm{~km}^{2}$ (Table 3 ). This corresponds with the largest decrease in the GLM pasture land unit (Table 2) and the increase in crops by $3.7 \times 10^{6} \mathrm{~km}^{2}$. The decreases in tree PFTs of $-0.3 \times$ $10^{6} \mathrm{~km}^{2}$ are relatively small compared to the tree changes in the other time series, consistent with maintaining constant forest area in the RCP. The tree PFT harvest area of $88.2 \times 10^{6} \mathrm{~km}^{2}$ is the second lowest of all RCPs. The RCP 6.0 global PFT land cover change maps (Figs. 4g and $4 \mathrm{~h}$ ) show mixed decreases in tree PFTs, reflecting the competing influences of changes in crops (Fig. 5g) and pastures, while the changes in grass PFTs follow the changes in pasture more directly.

The RCP 6.0 global map of tree PFT harvest (Fig. 5h) shows that the RCP has very high harvest prescription in many areas, with most of India and Europe being harvested more than twice in the period. The global PFT time series (Fig. 6) also shows that the RCP had large decreases in tree PFTs from 2010 to 2020 at the same time as increases in grasses. Further analysis found this to be the result of simultaneous increases in cropping in India replacing forests, which offset crop reductions in southern Russia, Europe, North America, and South America where secondary land was dominated by grasslands.

The RCP 8.5 time series has the largest decreases in tree PFTs of $-3.5 \times 10^{6} \mathrm{~km}^{2}$ (Table 3 ), reflecting the largest decreases in primary vegetation (forests) of all the RCPs (Table 2). The decrease in tree PFTs is associated with increases in crop area of $2.8 \times 10^{6} \mathrm{~km}^{2}$ and grass PFTs of $0.9 \times 10^{6} \mathrm{~km}^{2}$. The total area of tree PFT harvest at $123.2 \times 10^{6} \mathrm{~km}^{2}$ is the largest of all RCPs, with the 95-yr period harvesting over six times the area of trees harvested during the 150-yr historical period. The RCP 8.5 global PFT land cover change maps (Fig. 4i and 4j) show that decreases in tree PFTs follow increases in crop PFTs (Fig. 5i), while changes in grass PFTs more closely follow changes in pasture. The global map of tree PFT harvest (Fig. 5j) reflects the largest wood harvest prescription of the RCPs with high harvest areas extending from the tropics into higher latitudes.

\section{b. Historical and RCP biogeochemical impacts of transient land cover change}

The CCSM4 historical and RCP climate simulations were analyzed to understand the impacts of land cover change and wood harvest on the global carbon cycle within the full transient climate experiments. The average annual global fluxes of carbon are shown in Table 4, with the total changes in global carbon pools over the simulations shown in Table 5. These carbon fluxes and pools are the same as those shown in Fig. 2a. The geographic impacts of land cover change and wood harvest were investigated through global maps of average annual land use carbon flux (direct land cover change flux and product pool loss) and through the total change in ecosystem carbon over the simulation periods in Fig. 7. The global annual fluxes also were examined through time series plots of global annual averaged land use

TABLE 5. CMIP5 historical and RCP time series total change in global carbon pools (PgC) from CCSM4 full transient climate simulations. Variables shown are total ecosystem carbon excluding Product pools, product pool carbon, leaf carbon, wood carbon, fine root carbon, vegetation storage pools of nonstructural carbon, coarse woody debris carbon (CWD), litter carbon, and soil carbon.

\begin{tabular}{lrrrrrrrrr}
\hline \multicolumn{1}{c}{ Time series } & Ecosys & Product & Leaf & Wood & Root & Store & CWD & Litter & Soil \\
\hline Historical 1850-2005 & -64.49 & 8.36 & 0.48 & -73.61 & 1.22 & 3.03 & -9.20 & 0.82 & 12.77 \\
RCP 2.6 image & -24.49 & 5.90 & 0.23 & -40.66 & 0.88 & 3.41 & -4.61 & -0.75 & 17.01 \\
RCP 4.5 GCAM & 61.03 & 6.26 & 1.06 & 43.08 & 0.98 & 2.34 & 3.66 & -0.77 & 10.68 \\
RCP 6.0 AIM & 26.13 & 8.88 & 1.92 & 3.41 & 2.77 & 5.59 & -2.60 & 0.57 & 14.47 \\
RCP 8.5 message & -48.95 & 18.68 & 2.60 & -68.10 & 4.12 & 9.00 & -10.11 & 0.87 & 12.66 \\
\hline
\end{tabular}


(a) Historical (2005-1850) Land Use Flux

$\mathrm{gC} / \mathrm{m}^{2}$ lyear
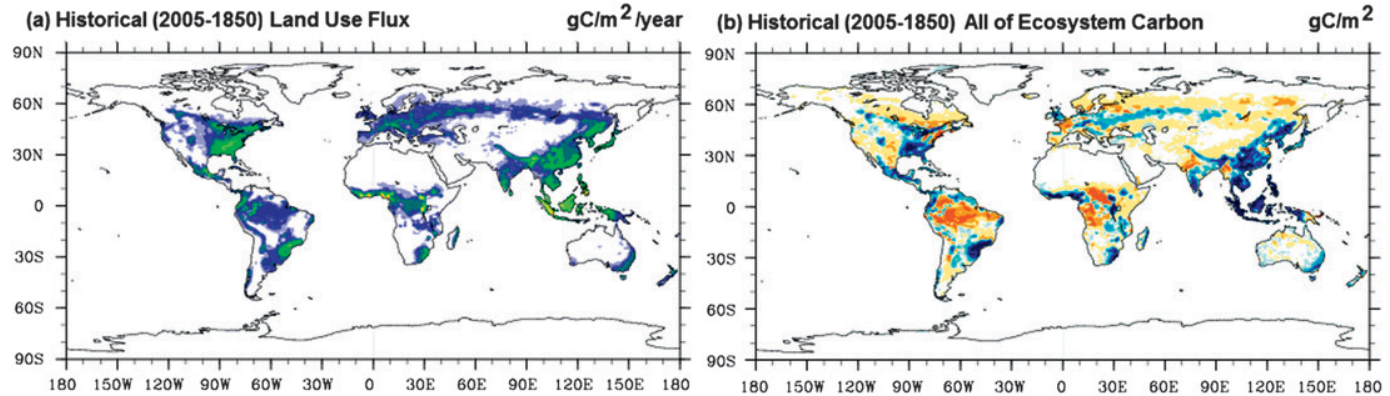

(c) RCP 2.6 IMAGE (2100-2006) Land Use Flux $\mathrm{gC} / \mathrm{m}^{2}$ /year

(d) RCP 26 IMAGE (2100-2006) All of Ecosystem Carbon $\mathrm{gC} / \mathrm{m}^{2}$
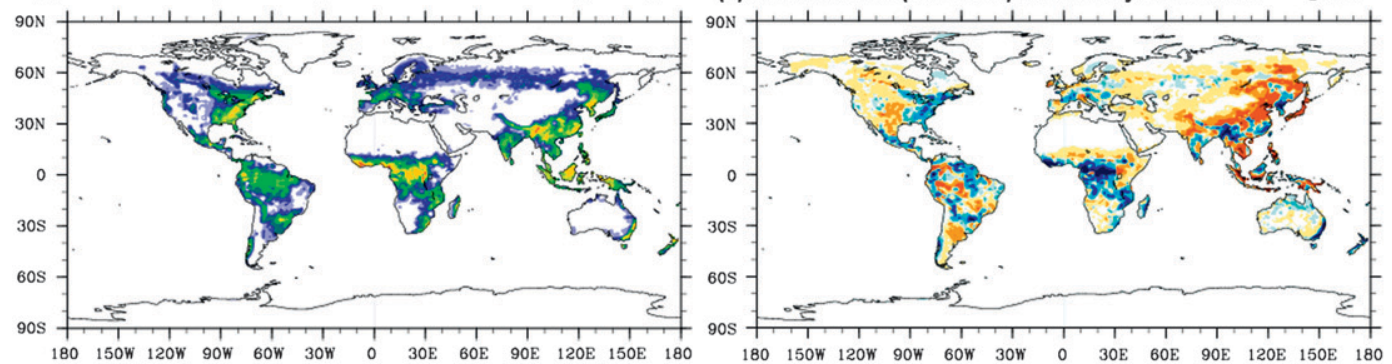
(e) RCP 4.5 MiniCAM (2100-2006) Land Use Flux $\quad \mathrm{gC} / \mathrm{m}^{2} /$ year

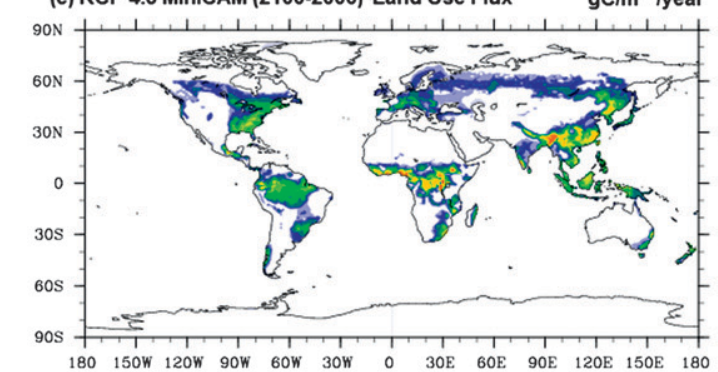

(f) RCP 4.5 MiniCAM (2100-2006) All of Ecosystem Carbon $\mathrm{gC} / \mathrm{m}^{2}$
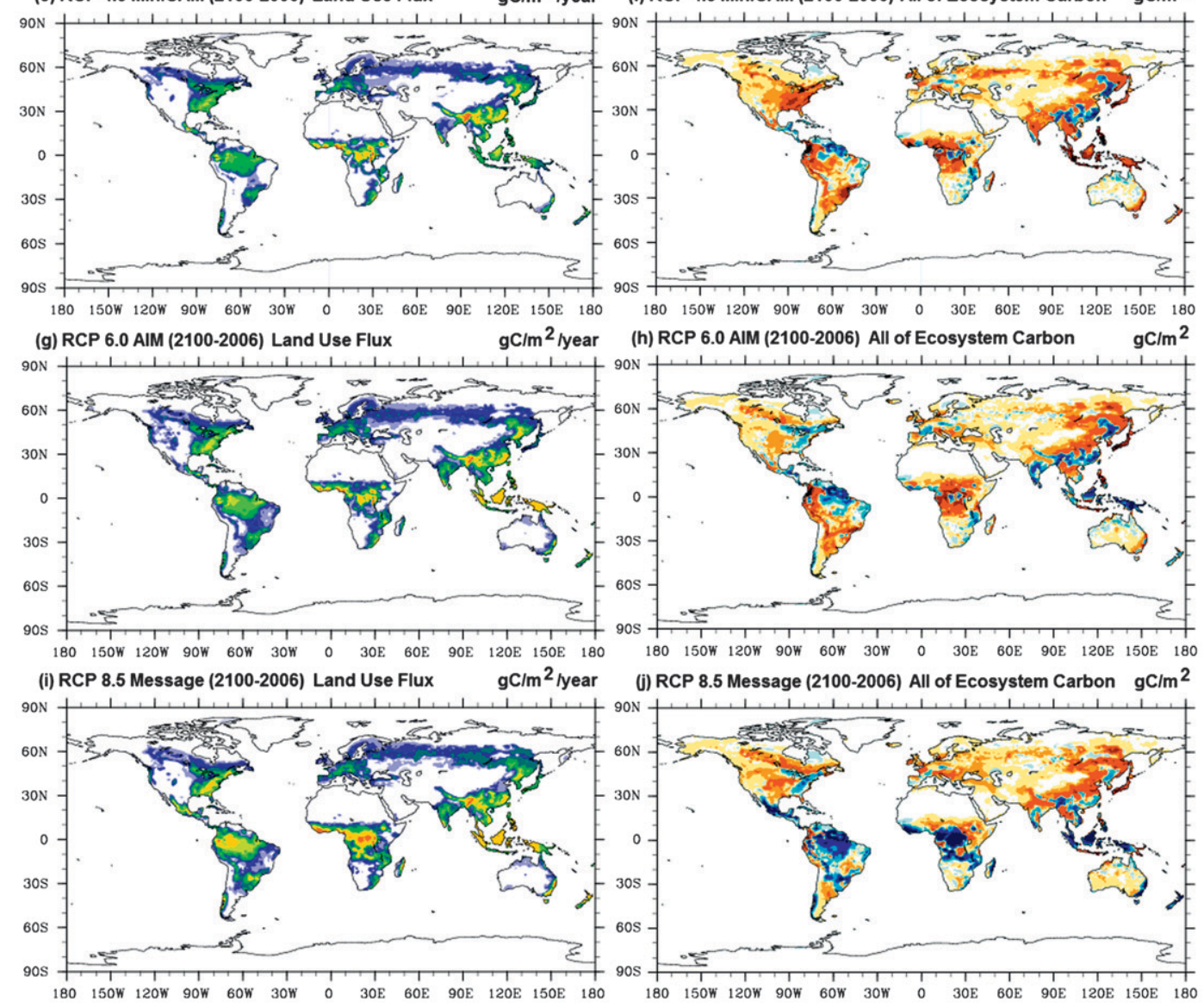

(i) RCP 8.5 Message (2100-2006) All of Ecosystem Carbon $\mathrm{gC} / \mathrm{m}^{2}$
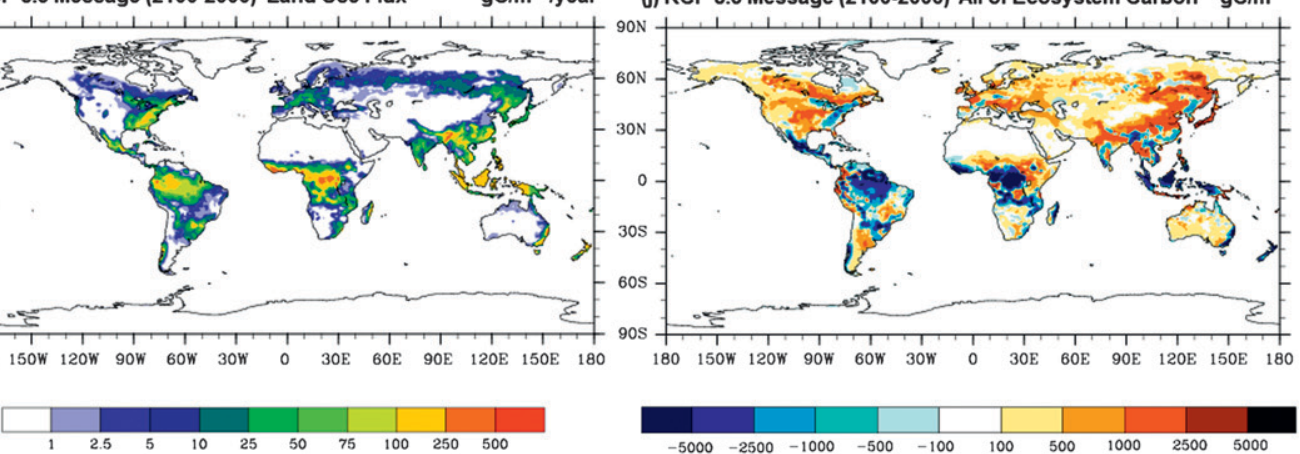

FIG. 7. CCSM4 full transient simulation average annual land use carbon flux and total change in all of ecosystem carbon for the CMIP5 historical and RCP periods. 
(a) CCSM 4.0 Global Total Land Cover Change Carbon Flux to Atmosphere

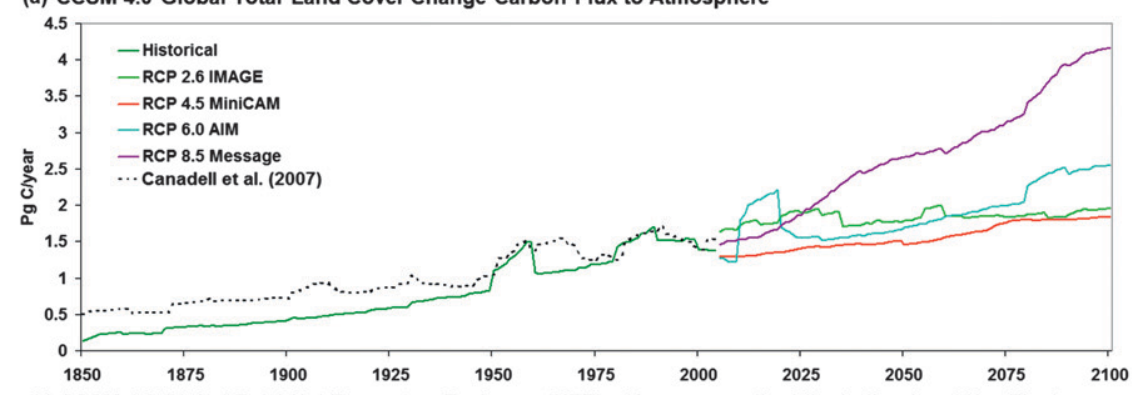

(b) CCSM 4.0 Global Total Net Ecosystem Exchange (NEE) - 10 year smoothed (Including Land Use Flux)

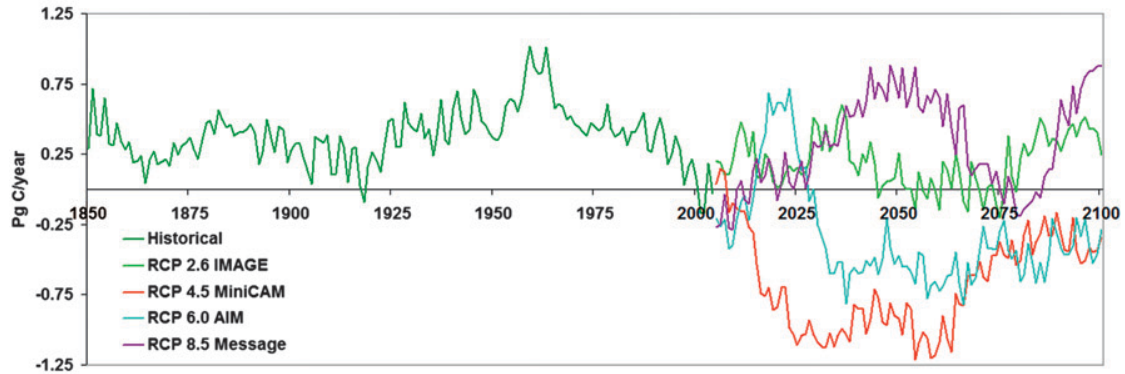

(c) CCSM 4.0 Global Total Wood Harvest Carbon Flux compared to GLM Harvest Carbon Flux

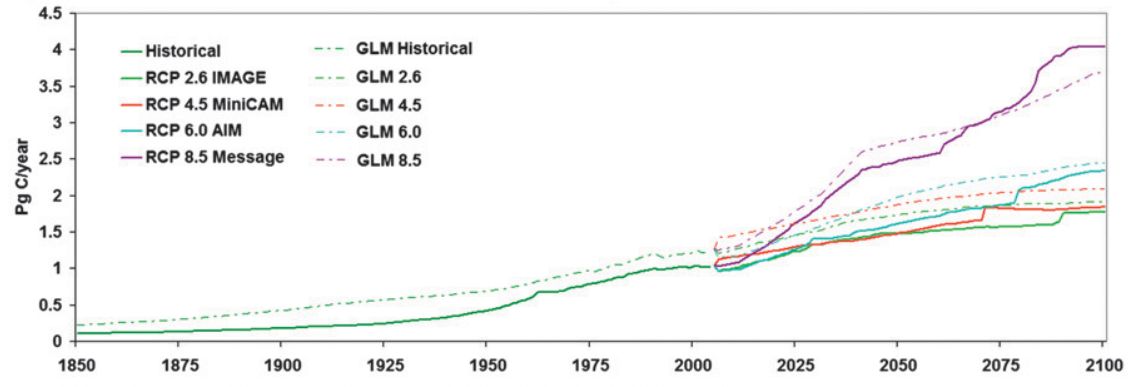

(d) CCSM 4.0 Global Total Ecosystem Carbon (Excluding Product Pools)

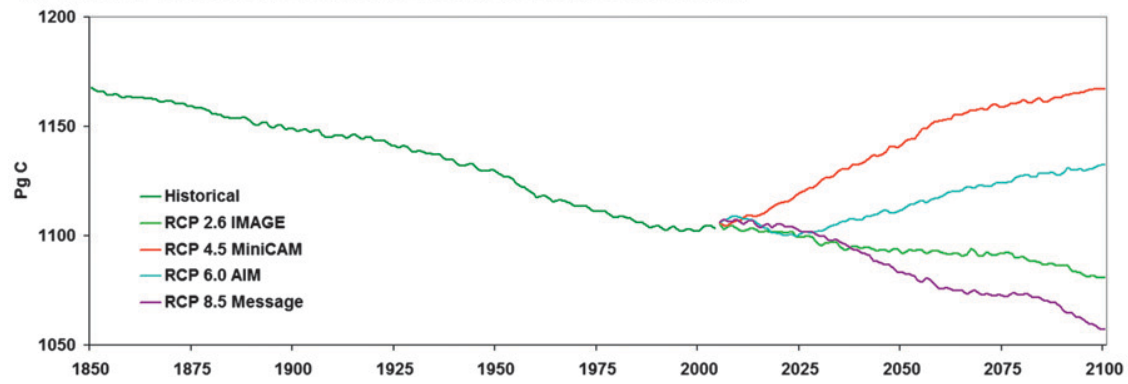

FIG. 8. CMIP5 global historical and RCP carbon fluxes of land use, net ecosystem exchange, and wood harvest and all of ecosystem carbon from CCSM4 full transient simulations.

carbon flux, net ecosystem exchange (NEE), and wood harvest carbon flux, and through changes in the global total ecosystem carbon pool in Fig. 8.

The historical global annual carbon fluxes of CCSM4 (Table 4) show that the model had an average global land use carbon flux of $0.76{\mathrm{PgC} \mathrm{yr}^{-1}}^{-1}$ over the historical period, which was partially offset by an effective ecosystem sink of carbon of $0.39 \mathrm{PgC} \mathrm{yr}^{-1}$, leaving an NEE flux to the atmosphere of $0.37 \mathrm{PgC}^{-1}$. The historical change in global carbon pools (Table 5) show the simulation lost $-64.5 \mathrm{PgC}$ of ecosystem carbon through a loss of $-73.6 \mathrm{PgC}$ of wood carbon and $-9.2 \mathrm{PgC}$ of coarse woody debris carbon. This was partially offset by an increase of $12.8 \mathrm{PgC}$ of soil carbon and smaller increases in leaf, fine root, litter, and vegetation storage carbon. At the end of the period the product pool had increased by $8.4 \mathrm{PgC}$ with the remaining $65.2 \mathrm{PgC}$ of ecosystem carbon released to the atmosphere. 
The global map of historical average annual land use flux (Fig. 7a) shows the land use fluxes were largest in eastern North America, China, Southeast Asia, with other major contributions from South America, western Europe, and central Africa. These areas correspond well with the largest losses of tree PFTs (Fig. 4a) and tree PFT harvest (Fig. 5b). The areas of largest land use flux also correspond with the largest decreases in ecosystem carbon (Fig. 7b). In areas with low or no land use flux, however, the simulation had increased ecosystem carbon through the period, reflecting the influence of other forcings in the full transient run such as increased atmospheric $\mathrm{CO}_{2}$, increased nitrogen deposition, and lengthened growing season from warming in higher latitudes.

The time series plots show that the CCSM4 historical land use flux was consistent, but lower than the global annual estimates of Canadell et al. (2007) (Fig. 8a) for the entire period, and that the wood harvest carbon flux was consistent with the CMIP5 GLM historical values (Fig. 8c). The CCSM4 NEE flux was positive to the atmosphere for most of the historical period, reaching a maximum value of $1 \mathrm{PgC} \mathrm{yr}^{-1}$ in 1960 before returning to $0.0 \mathrm{PgC} \mathrm{yr}^{-1}$ by 2005 . The positive NEE is consistent with the decline in ecosystem carbon throughout the period (Fig. 8d).

The CCSM4 average annual RCP 2.6 carbon fluxes (Table 4) show that this simulation had the lowest wood harvest flux at $1.43 \mathrm{PgC} \mathrm{yr}^{-1}$ and the second lowest land use flux of all RCPs at $1.84 \mathrm{PgC} \mathrm{yr}^{-1}$. The RCP 2.6 average land use flux was over twice the historical value, while the wood harvest flux was over three times the average historical value. Despite this, the RCP 2.6 simulation only had half of the historical NEE flux at 0.18 $\mathrm{PgC} \mathrm{yr}{ }^{-1}$. This made it the lower of the two RCPs with positive releases of carbon, with only RCP 8.5 having a larger loss of carbon. The reduction in NEE compared to the historical simulation was the result of increased net primary production (NPP), which partially offset the increases in land use and heterotrophic respiration.

The change in RCP 2.6 global carbon pools (Table 5) reflects the relative differences in NEE with a loss of ecosystem carbon of $-24.5 \mathrm{PgC}$. This was the smaller loss of ecosystem carbon of the simulations with positive NEE with RCP 8.5 losing substantially more carbon. The loss of ecosystem carbon came from a $-40.7 \mathrm{PgC}$ loss of wood carbon and a $-4.6 \mathrm{PgCl}$ loss of coarse woody debris carbon. These decreases both were about half of the losses of these pools in the historical simulation. The RCP 2.6 simulation also had an increase in soil carbon of $17.0 \mathrm{PgC}$, which was the largest increase in soil carbon of all simulations. There also was an increase in the product pool of $5.9 \mathrm{PgC}$ with the remaining $18.6 \mathrm{PgC}$ of ecosystem carbon released to the atmosphere.
The RCP 2.6 global map of land use flux (Fig. 7c) shows that land use carbon flux was largest in eastern North America, central Africa, Southeast Asia, and China, with smaller land use fluxes in Europe, South America, and India. The RCP 2.6 global map of ecosystem carbon change (Fig. 7d) shows carbon was only lost in eastern North America and central Africa with South America, China, Southeast Asia, and India all having mixed impacts with equal areas of carbon increases offsetting decreases in ecosystem carbon.

The time series plots show that the RCP 2.6 simulation had both land use and wood harvest fluxes increasing through the period at rates consistent with the increases seen in the historical period (Figs. 8a and 8c). The CCSM4 RCP 2.6 wood harvest flux was consistent with the CMIP5 GLM specified wood harvest flux for the entire period. The RCP 2.6 NEE flux was positive for much of the period but at values below $0.8 \mathrm{PgC}^{-1}$, resulting in a decrease in ecosystem carbon that also was consistent with the rate of decrease in the historical simulation (Figs. 8b and 8d).

The RCP 4.5 global annual carbon fluxes (Table 4) show that this CCSM4 simulation had a NEE flux of $-0.69{\mathrm{PgC} \mathrm{yr}^{-1}}^{-}$. This was the largest drawdown of carbon of the CCSM4 simulations. The negative NEE was the result of higher NPP and the lowest land use flux of the RCPs at $1.56 \mathrm{PgC}^{-1}$. The low land use flux was caused by the low wood harvest of $1.52 \mathrm{PgC} \mathrm{yr}^{-1}$ and carbon uptake through reforestation. The changes in global carbon pools (Table 5) show that the negative NEE resulted in an increase in ecosystem carbon of $61.0 \mathrm{PgC}$. This was the largest increase in ecosystem carbon of the RCP simulations with the increase coming mostly from increases in wood of $43.1 \mathrm{PgC}$ and coarse woody debris of $3.7 \mathrm{PgC}$. The product pool carbon also increased by $6.3 \mathrm{PgC}$, simulating $67.3 \mathrm{PgC}$ being removed from the atmosphere over the simulation.

The global map of RCP 4.5 land use carbon flux (Fig. 7e) has a similar spatial pattern to RCP 2.6 (Fig. 7c) but with lower values. The RCP 4.5 map of change in ecosystem carbon (Fig. 7f), however, shows that RCP 4.5 had large uptakes in carbon, whereas RCP 2.6 had large losses of carbon. These areas are associated with increases in tree PFTs in RCP 4.5 compared to tree losses in RCP 2.6 (Figs. 4c and 4e). The time series plots show that RCP 4.5 had consistently lower land use flux to the atmosphere than RCP 2.6 despite similar wood harvest fluxes (Figs. 8a and 8c). The lower land use flux resulted in negative NEE for the whole period, with NEE reaching a maximum value of $-1.25 \mathrm{PgC} \mathrm{yr}^{-1}$ in 2060 before being reduced to less than $-0.25 \mathrm{PgC} \mathrm{yr}^{-1}$ by 2100 (Fig. 8b). The negative NEE flux resulted in increased ecosystem carbon for the entire period (Fig. 8d). 
The RCP 6.0 average annual carbon fluxes (Table 4) show that this simulation had a land use flux of 1.90 $\mathrm{PgC} \mathrm{yr}^{-1}$, which was marginally larger than the RCP 2.6 and RCP 4.5 fluxes. The land use flux largely comprised of the wood harvest flux of $1.65 \mathrm{PgC} \mathrm{yr}^{-1}$, which was again higher than the RCP 2.6 and RCP 4.5 fluxes. Despite the higher land use flux, the larger increase in NPP resulted in the second largest negative NEE flux of the RCPs at $-0.35 \mathrm{PgC} \mathrm{yr}^{-1}$. The changes in RCP 6.0 global carbon pools (Table 5) show that the CCSM4 simulation had a gain of ecosystem carbon of $26.1 \mathrm{PgC}$. The ecosystem carbon gain was through increases in leaf, wood, root, vegetation storage, and soil carbon, which offset a loss of coarse woody debris carbon. The product pool carbon increased by $8.9 \mathrm{PgC}$ over the RCP 6.0 simulation with a net removal of $35.0 \mathrm{PgC}$ from the atmosphere.

The global map of RCP 6.0 land use flux (Fig. 7g) shows the same spatial patterns as RCP 2.6 and RCP 4.5 (Figs. 7c and 7e) but with higher values in South America, central Africa, China, and Southeast Asia, with smaller increases in North America, Europe, and Australia. The RCP 6.0 change in ecosystem carbon map (Fig. 7h) shows similar spatial patterns only to RCP 4.5 (Fig. 7f), but with carbon losses replacing gains in eastern North America, South America, and India. The time series plots show that RCP 6.0 had a large jump in land use flux at the start of the period (Fig. 8a), starting at $1.5 \mathrm{PgC} \mathrm{yr}^{-1}$ in 2006 and reaching $2.3 \mathrm{PgC} \mathrm{yr}^{-1}$ by 2019, coincident with the increases in wood harvest and grass PFT area. After this initial increase the land use flux falls before slowly ramping up to $2.5 \mathrm{PgC}^{-1}$ at 2100. The wood harvest flux plot (Fig. 8c) shows that RCP 6.0 slowly rises from $1.0 \mathrm{PgC} \mathrm{yr}^{-1}$ in 2005 to reach $2.2 \mathrm{PgC} \mathrm{yr}^{-1}$ by 2100 .

The large increase in land use flux at the beginning of the RCP 6.0 simulation resulted in an NEE flux that increased to $0.75 \mathrm{PgC} \mathrm{yr}^{-1}$ by 2021 (Fig. 8b). The NEE flux then declined to around $-0.75 \mathrm{PgC} \mathrm{yr}^{-1}$ by 2035 before decreasing in magnitude to about $-0.5 \mathrm{PgC} \mathrm{yr}^{-1}$ for the remainder of the time series. The decline in NEE flux after 2035 occurred despite the increase in land use and wood harvest fluxes over the period. The time evolution of the NEE flux is reflected in the ecosystem carbon, which declined slightly to 2025 before increasing through the rest of the simulation (Fig. 8d).

The RCP 8.5 global annual carbon fluxes (Table 4) show this CCSM4 simulation had the highest land use flux of all the RCPs at 2.7 $\mathrm{PgC} \mathrm{yr}^{-1}$. This was over three times the historical land use flux and one and a half times the land use fluxes of the other RCPs. The RCP 8.5 wood harvest flux also was the largest of the RCPs at $2.54{\mathrm{PgC} \mathrm{yr}^{-1}}^{-1}$. This was six times the historical wood harvest flux and one and a half times the wood harvest fluxes of the other RCPs. The higher land use flux also resulted in the largest positive NEE flux of the RCPs at $0.38 \mathrm{PgC} \mathrm{yr}^{-1}$, which was nearly the same as the historical flux to the atmosphere.

The changes in RCP 8.5 global carbon pools (Table 5) show that the simulation had the largest decrease in ecosystem carbon of the RCPs with a total loss of $-49.0 \mathrm{PgC}$. This was twice the decrease in RCP 2.6 but still smaller than the historical simulation. The ecosystem carbon loss was primarily from a decrease in wood carbon of $-68.1 \mathrm{PgC}$ and a decrease in coarse woody debris carbon of $-10.1 \mathrm{PgC}$. These losses were partially offset by increases in other carbon pools. The large wood harvest flux resulted in the largest increase in the product pool of $18.7 \mathrm{PgC}$ with a net release of ecosystem carbon to the atmosphere of $30.3 \mathrm{PgC}$.

The RCP 8.5 global map of land use flux (Fig. 7i) shows a similar spatial pattern to RCP 6.0 but with large increases in South America and Africa and with smaller increases in China, Southeast Asia, North America, Europe, and Australia. These changes also are reflected in the RCP 8.5 map of changes in ecosystem carbon (Fig. 7j) where carbon losses are much larger than RCP 6.0 in South America and central Africa but similar over the rest of the world. The time series plots show RCP 8.5 had a steady increase in land use flux over the simulation, rising to a maximum flux of $4.0 \mathrm{PgC} \mathrm{yr}^{-1}$ in 2100 (Fig. 8a). The higher land use flux comes from a higher wood harvest carbon flux that starts at 1 and reaches $4.2 \mathrm{PgC} \mathrm{yr}^{-1}$ in 2100 (Fig. 8c).

The higher land use and wood harvest fluxes are reflected in the RCP 8.5 NEE flux time series (Fig. 8b), which rises to $0.75 \mathrm{PgC} \mathrm{yr}^{-1}$ by 2050 then declines to around $0.0 \mathrm{PgC} \mathrm{yr}^{-1}$ by 2075 before rising again to $0.75 \mathrm{PgC} \mathrm{yr}^{-1}$ in 2100 . The higher land use and wood harvest fluxes ensure the NEE flux remained elevated longer in RCP 8.5 than in RCP 2.6. The high positive NEE flux also is reflected in the continual loss of ecosystem carbon throughout the simulation (Fig. 8d).

\section{c. Historical biogeophysical impacts of transient land cover change}

The historical CCSM4 land-cover-change-only and full transient climate simulations were analyzed to understand the biogeophysical impacts of land cover change and wood harvest on CCSM4 land surface climate. The differences in annual land surface climate variables of the last $30 \mathrm{yr}$ of the time series are compared to the first $30 \mathrm{yr}$ in Table 6 for global land, and the regions of the eastern United States, China, and India, with statistical significance calculated with a paired Student's $t$ test. The radiation and heat fluxes are the same as those 
TABLE 6. CMIP5 historical biogeophysical changes in global and regional annual climate variables for CCSM4 land-cover-change-only and full transient climate simulations for the periods (1976-2005) - (1850-79). Variables are shortwave land surface albedo (fraction), near-surface land temperature (Temp), leaf area index (LAI), land precipitation (Precip), land-absorbed shortwave radiation (SWR), land net longwave radiation (LWR), land sensible heat flux, and land latent heat flux. Land shortwave radiation flux is positive into the surface; all other fluxes are positive out of the surface.

\begin{tabular}{|c|c|c|c|c|c|c|c|c|c|}
\hline Region & Simulation & Albedo & $\begin{array}{l}\text { Temp } \\
\left({ }^{\circ} \mathrm{C}\right)\end{array}$ & $\begin{array}{c}\text { LAI } \\
\left(\mathrm{m}^{2} \mathrm{~m}^{-2}\right)\end{array}$ & $\begin{array}{c}\text { Precip } \\
\left(\mathrm{mm} \mathrm{day}^{-1}\right)\end{array}$ & $\begin{array}{c}\mathrm{SWR} \\
\left(\mathrm{W} \mathrm{m} \mathrm{m}^{-2}\right)\end{array}$ & $\begin{array}{c}\mathrm{LWR} \\
\left(\mathrm{W} \mathrm{m}{ }^{-2}\right)\end{array}$ & $\begin{array}{l}\text { Sensible } \\
\left(\mathrm{W} \mathrm{m}^{-2}\right)\end{array}$ & $\begin{array}{c}\text { Latent } \\
\left(\mathrm{W} \mathrm{m}^{-2}\right)\end{array}$ \\
\hline \multirow[t]{2}{*}{ Global } & Land cover & $0.0021 *$ & $-0.10^{*}$ & $-0.04 *$ & -0.005 & $-0.28 *$ & -0.09 & -0.09 & -0.11 \\
\hline & Full transient & $-0.0019^{*}$ & $0.98^{*}$ & $0.11 *$ & 0.007 & $-1.36^{*}$ & $-1.68 *$ & 0.29 & -0.00 \\
\hline \multirow[t]{2}{*}{ Eastern U.S. } & Land cover & $0.0062 *$ & $-0.45^{*}$ & 0.05 & 0.098 & $-3.09 *$ & $-1.73^{*}$ & $-1.26^{*}$ & -0.14 \\
\hline & Full transient & $0.0028 *$ & $0.45^{*}$ & $0.45^{*}$ & 0.051 & $-3.32 *$ & $-2.89 *$ & $-1.38^{*}$ & $0.96^{*}$ \\
\hline \multirow[t]{2}{*}{ China } & Land cov & $0.0041 *$ & -0.03 & $-0.31 *$ & $-0.144^{*}$ & 1.47 & $1.67 *$ & 0.11 & -0.32 \\
\hline & Full transient & $0.0035^{*}$ & $0.68 *$ & $0.20 *$ & -0.026 & $-5.92 *$ & $-2.36^{*}$ & $-2.95^{*}$ & -0.59 \\
\hline \multirow[t]{2}{*}{ India } & Land cover & $0.0026^{*}$ & -0.09 & -0.04 & 0.067 & $-1.88^{*}$ & -1.21 & -1.67 & 1.04 \\
\hline & Full transient & $0.0038^{*}$ & $0.85^{*}$ & -0.06 & -0.084 & $-3.60 *$ & $-1.87^{*}$ & -0.14 & -1.62 \\
\hline
\end{tabular}

* Statistical significance in difference between the periods (1976-2005) - (1850-79): Student's $t$ test significance $\geq 0.95$.

shown in Figs. 2b and 2c. These differences also are shown in the global maps of Fig. 9 and in the time series analyses of annual differences in the global variables relative to $1850-59$ mean values in Fig. 10.

The analysis of changes in global annual averaged land surface climate (Table 6) show the land-coverchange-only experiment had an increase in global annual averaged land surface albedo of 0.002 , with a decrease of land-absorbed shortwave radiation (SWR) of $-0.28 \mathrm{~W} \mathrm{~m}^{-2}$ and an associated cooling of nearsurface land temperature of $-0.1^{\circ} \mathrm{C}$. The full transient experiment, on the other hand, had a decrease in land surface albedo of -0.002 and an increase in near-surface land temperature of $0.98^{\circ} \mathrm{C}$, despite a much larger decrease in absorbed shortwave radiation of $-1.36 \mathrm{~W} \mathrm{~m}^{-2}$.

The larger decrease in global annual-averaged absorbed shortwave radiation in the full transient experiment was the result of higher aerosol loadings and other atmospheric forcing, which had a larger impact than the decrease in surface albedo. The warming in the full transient experiment with lower absorbed shortwave radiation was the result of a larger decrease in net longwave radiation (LWR) from the surface due to other forcings, such as atmospheric $\mathrm{CO}_{2}$, with the net result an increase in the land surface radiation budget. The opposite was true in the land-cover-change-only experiment in which the decrease in net outgoing longwave radiation was smaller than the decrease in absorbed shortwave radiation, resulting in a net decrease in the land surface radiation budget and cooling.

The land-cover-change-only experiment had a decrease in global annual averaged leaf-area index (LAI) of -0.04 , while the full transient experiment had an increase of 0.11 . The increase in LAI in the full transient experiment despite the land cover change and wood harvest prescription indicates that other forcings on vegetation, such as $\mathrm{CO}_{2}$ fertilization, atmospheric nitrogen deposition, and longer high-latitude growing seasons, had a larger impact on vegetation growth in the CLM-CN model than land cover change. The land-coverchange-only experiment also had statistically nonsignificant decreases in precipitation and sensible and latent heat fluxes, while the full transient experiment had nonsignificant increases in precipitation and sensible heat flux.

The global maps of changes in annual-averaged land surface albedo (Figs. 9a and 9b) show that the landcover-change-only experiment had the largest increases in albedo in North America, eastern Europe through Russia, and in China. The largest increases in albedo also were present in the full transient experiment but were smaller than the decreases in albedo in snow covered higher northern latitudes and over the Tibetan Plateau. The global annual-averaged time series plots of land surface albedo (Fig. 10a) show the land-coverchange-only experiment had albedo increasing consistently through the historical period, while the full transient experiment had changes in albedo closely tied to land surface temperature (Fig. 10b) with warming accompanying decreased albedo and cooling accompanying increased albedo.

The global maps of changes in near-surface land temperature show the land-cover-change-only experiment had the largest cooling in North America and in northern Siberia with mixed changes elsewhere. The full transient experiment by contrast had the largest warming at high latitudes corresponding with the decrease in albedo in snow-covered areas. In the eastern United States and China warming was smaller, corresponding with the areas that had increased albedo in both 
(a) Full Transient - Change in Albedo

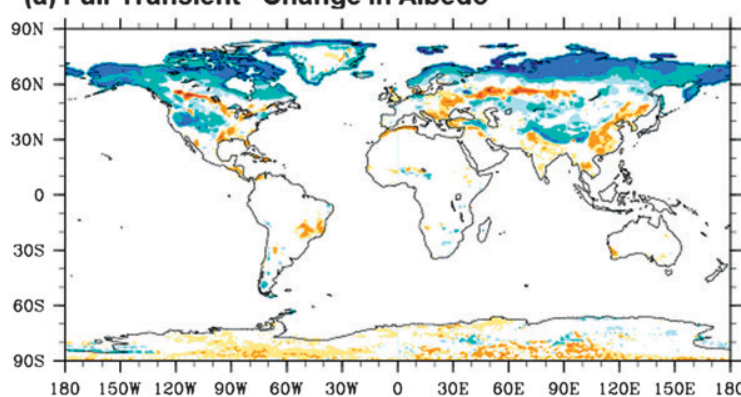

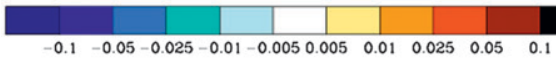

(c) Full Transient - Change in $2 \mathrm{~m}$ Temperature Deg $\mathrm{C}$

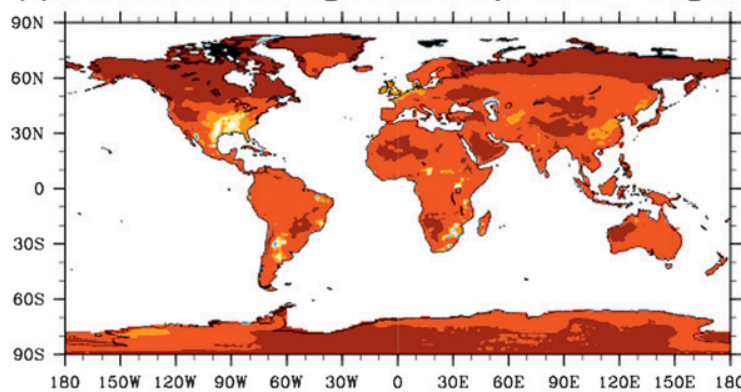

\begin{tabular}{llll|l|l|l|l|l|l}
\hline & & & & & & & & & \\
\hline-2.5 & -1 & -0.5 & -0.25 & -0.1 & 0.1 & 0.25 & 0.5 & 1 & 2.5
\end{tabular}

(e) Full Transient - Change in Leaf Area Index $\mathrm{m}^{2} / \mathrm{m}^{2}$

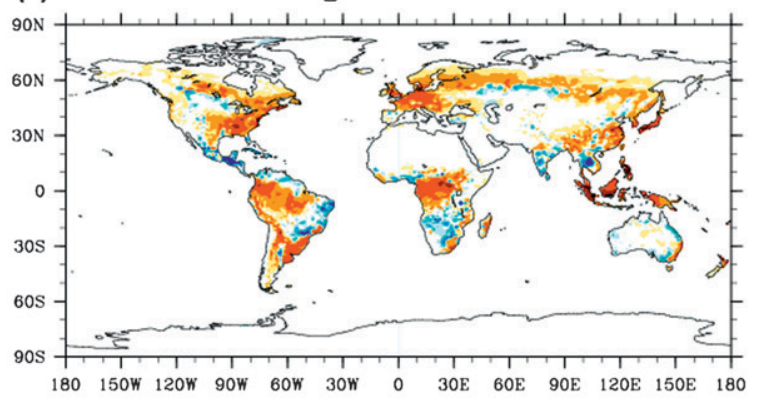

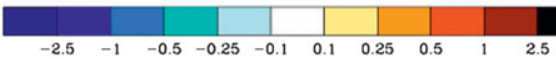

(g) Full Transient - Change in Precipitation $\mathrm{mm} /$ day

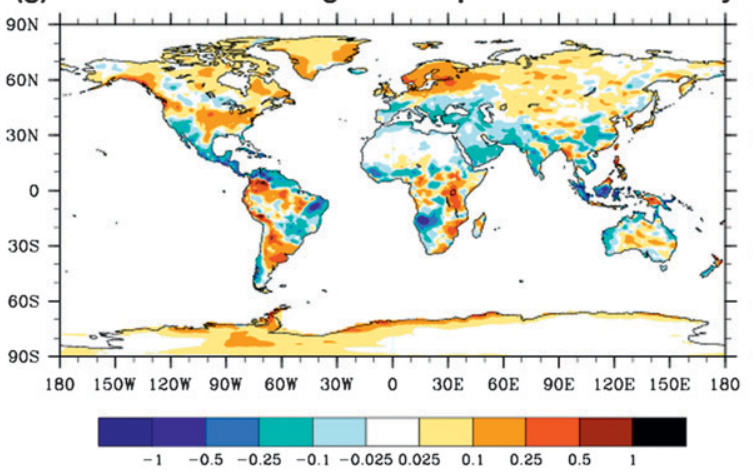

(b) Land Cover Change Only - Change in Albedo

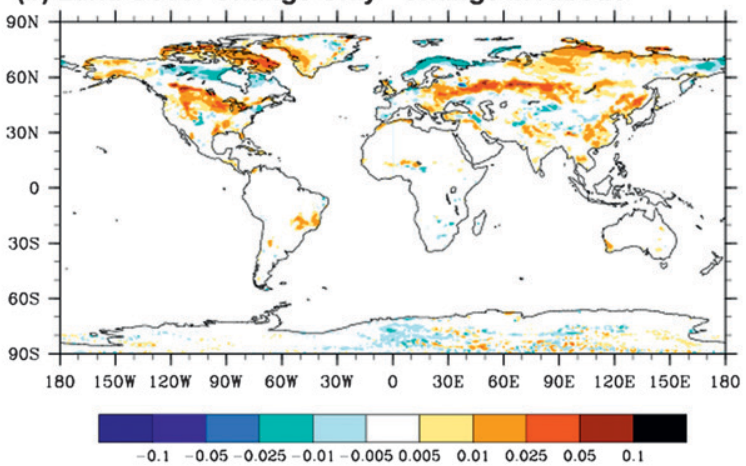

(d) Land Cover Change Only - Change in $2 \mathrm{~m}$ Temp Deg C

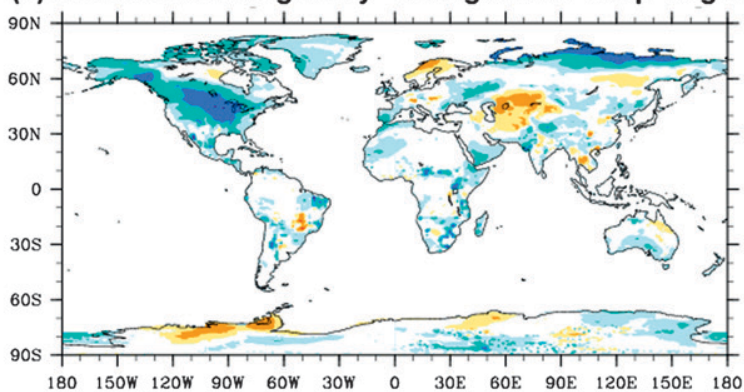

\begin{tabular}{lll|l|l|l|l|l|l|l|l|}
\hline & & & & & & & & & & \\
\hline
\end{tabular}

(f) Land Cover Change Only - Change in LAl $\mathrm{m}^{2} / \mathrm{m}^{2}$

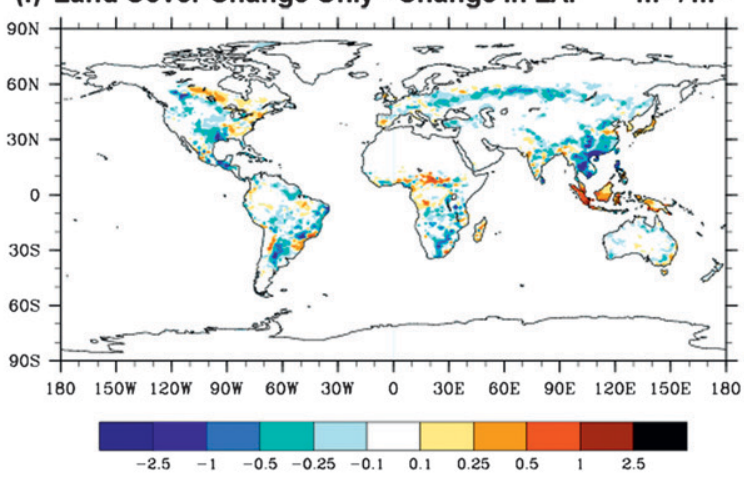

(h) Land Cover Only - Change in Precip mm/day

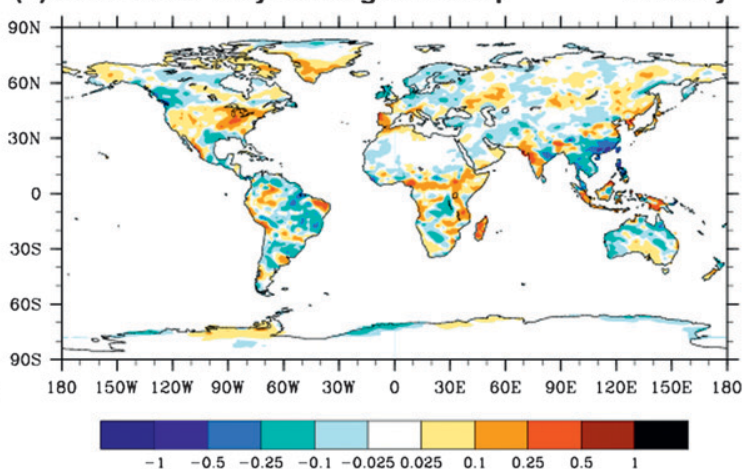

FIG. 9. CMIP5 historical biogeophysical changes in annual surface albedo, near-surface land temperature, leaf area index (LAI), and land precipitation from the CCSM4 full transient and land cover change-only climate simulations (1976-2005) - (1850-79). 
(a) CCSM 4.0 Change in Global Annual Averaged Shortwave Land Surface Albedo - 10 year smoothed

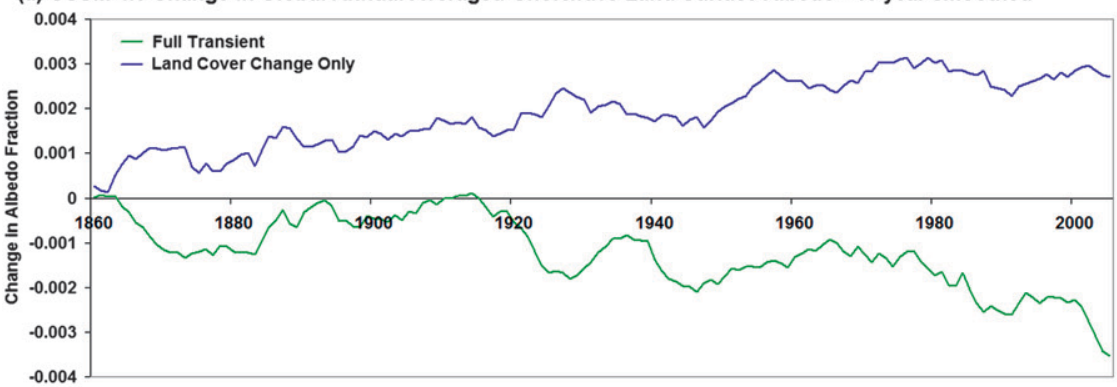

(b) CCSM 4.0 Change in Global Annual Averaged Land Air Temperature - 10 year smoothed

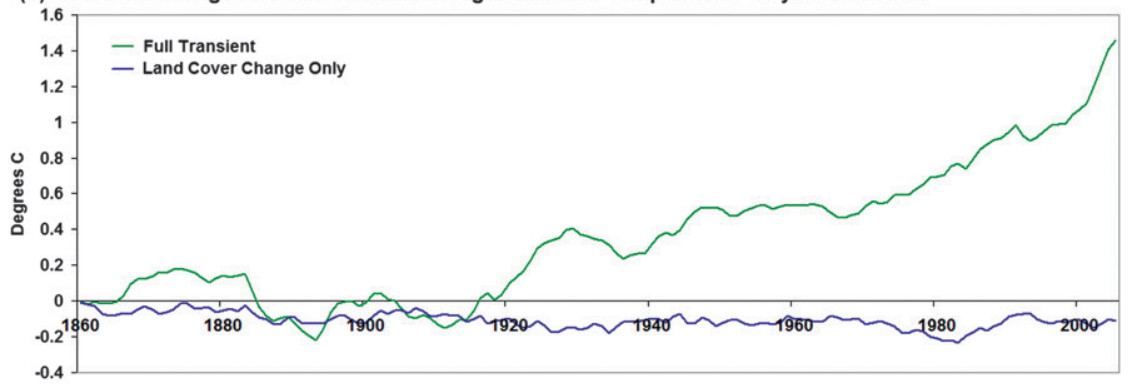

(c) CCSM 4.0 Change in Global Annual Averaged Leaf Area Index (LAI) - 10 year smoothed

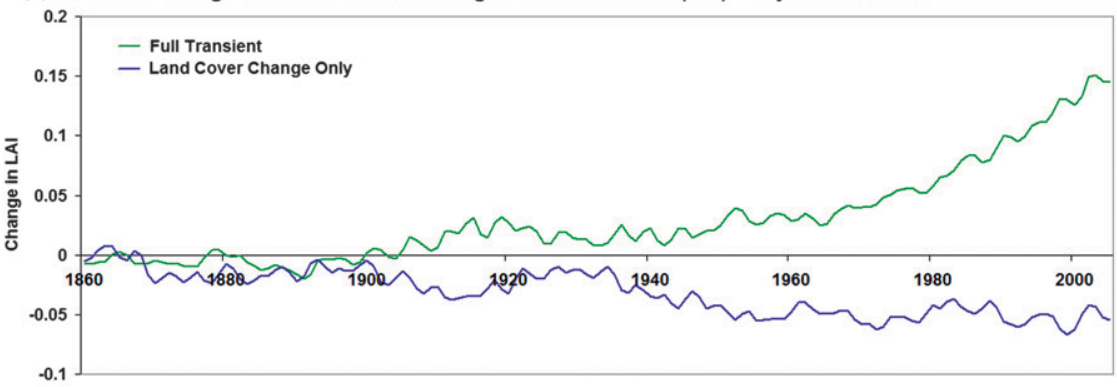

(d) CCSM 4.0 Change in Global Annual Averaged Land Precipitation - 10 year smoothed

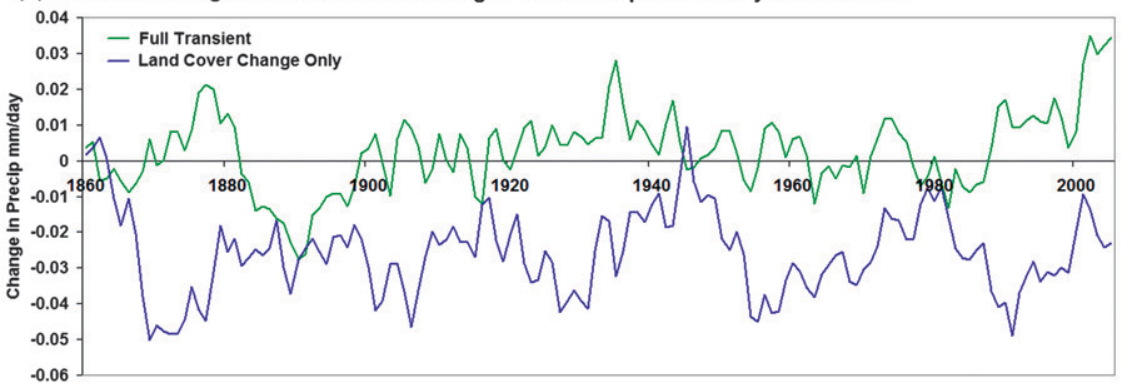

FIG. 10. CMIP5 global historical changes in annual land surface broadband albedo, land air temperature, LAI, and land precipitation for CCSM4 full transient and land cover change-only simulations smoothed with a 10-yr running mean relative to the $1850-59$ period.

experiments. The global time series plots of near-surface land temperature (Fig. 10b) showthat the land-coverchange-only experiment had a gradual cooling through the historical period, whereas the full transient experiment demonstrated the competing forcings of atmospheric greenhouse gases, aerosols, and land cover change, with periods of warming and cooling before stronger warming from 1920 to 2005.
The global maps of changes in annual averaged LAI (Figs. 9e and 9f) showthat the land-cover-change-only experiment had the largest decreases in LAI in areas where tree PFTs decreased (Fig. 4a). The full transient experiment, however, had widespread increases in LAI with the largest increases in North America, western Europe, South America, central Africa, and Indonesia. The global time series plots of LAI (Fig. 10c) show that 
both experiments initially had decreases in LAI until 1900 with only the land cover change experiment continuing to decrease LAI to 2005. The full transient experiment, however, had gradually increasing LAI from 1900 to 1965 before ramping up dramatically for the last $40 \mathrm{yr}$ of the period.

The global maps of changes in annual averaged precipitation (Figs. 9g and 9h) show the regional nature of precipitation change in the land cover change experiment compared to the more zonal precipitation changes in the full transient experiment. The largest responses in the land-cover-change-only experiment were increased precipitation in North America and decreased precipitation in South America and China. In the full transient experiment, however, precipitation increased at higher latitudes, decreased from the equator to $30^{\circ} \mathrm{N}$, and was mixed south of the equator. The global time series of precipitation (Fig. 10d) shows that the land-cover-changeonly experiment had an initial decrease in precipitation and stayed lower, oscillating around a $-0.03 \mathrm{~mm}$ day $^{-1}$ change. The full transient experiment, however, oscillated around a $0 \mathrm{~mm} \mathrm{day}{ }^{-1}$ change for most of the historical period before ramping up to an increase of $0.03 \mathrm{~mm} \mathrm{day}^{-1}$ from 1980 to 2005 .

The CCSM4 biogeophysical regional analysis (Table 6) shows that all regions had increased annual-averaged land surface albedo for both experiments, although the magnitude of the increase varied by region and experiment. The land-cover-change-only experiment also had decreases in annual-averaged near-surface land temperature for all three regions, while the full transient experiment had increased temperature for all regions.

In the eastern United States, the land-cover-changeonly experiment cooled by $-0.45^{\circ} \mathrm{C}$ and had three times the albedo increase as the full transient experiment that warmed by $0.45^{\circ} \mathrm{C}$. Despite the larger increase in annual-averaged surface albedo, the land-cover-changeonly experiment had a smaller decrease in shortwave radiation absorbed, demonstrating the combined impacts of land cover with other forcings in the full transient experiment. The decrease in longwave radiation in the land-cover-change-only experiment also was smaller than the full transient experiment, with the net result a larger decrease in surface radiation budget in the landcover-change-only experiment.

The decreases in sensible heat flux were similar in both experiments despite very different surface energy balance changes. The reduced latent heat flux in the land-cover-change-only experiment offset some of the decrease in surface radiation budget, whereas increased latent heat flux combined with a smaller decrease in surface radiation budget in the full transient experiment. The increase in latent heat flux in the full transient experiment was consistent with the higher LAI found in the experiment and provides an explanation as to why the eastern United States warmed less than the global average and the other three regions, as shown in the global map (Fig. 9).

In the China region, annual-averaged albedo increases were closer between the two experiments, but the changes in absorbed shortwave radiation were larger. In the land-cover-change-only experiment, the increase in albedo was accompanied by an increase in absorbed shortwave radiation of $1.47 \mathrm{~W} \mathrm{~m}^{-2}$, whereas in the full transient experiment the absorbed shortwave radiation decreased by $-5.92 \mathrm{~W} \mathrm{~m}^{-2}$. These differences reflected the impact of changes in atmospheric conditions in both experiments, with reduced cloudiness in the landcover-change-only experiment (not shown) having a larger impact on the shortwave radiation than albedo, whereas in the full transient experiment the increased albedo combined with higher aerosol loadings and cloud cover to further reduce the shortwave radiation absorbed.

The changes in outgoing longwave radiation between the experiments also impacted the surface radiation budget changes. In the land-cover-change-only experiment, the reduced cloudiness and water vapor resulted in increased outgoing longwave radiation, leaving a small decrease in net surface radiation. In the full transient experiment, however, the reduction in outgoing longwave radiation due to increased greenhouse gases was smaller than the reduction in absorbed shortwave radiation, resulting in a greater reduction in net surface radiation. The differences in net surface radiation changes were evident in the surface turbulent heat fluxes, with the land-cover-change-only experiment having a small increase in sensible heat flux and the full transient experiment having a large decrease in sensible heat flux.

In the India region, the land-cover-change-only experiment had a smaller increase in surface albedo than the full transient experiment. This difference was primarily due to the impact of drier soils (not shown) on soil reflectance in the full transient experiment. Again, changes in atmospheric conditions between the experiments influenced the impact of albedo on absorbed shortwave radiation. The full transient experiment had twice the reduction in absorbed shortwave radiation, with the higher albedo combining with the increased aerosol loading.

The decrease in outgoing longwave radiation was only marginally higher in the full transient experiment, so the reduction in net surface radiation was larger in the full transient experiment. Despite the decrease in net surface radiation in the full transient experiment, the impact on surface energy fluxes was primarily realized through decreased latent flux with only a small decrease 
in sensible heat flux. This resulted in the largest warming of the three regions in the full transient analysis. The warming of the near-surface temperature in the full transient experiment despite a decrease in sensible heat flux was a product of advection of warmer air from the surrounding areas (not shown). In the land-cover-changeonly experiment the decrease in net surface radiation combined with the increase in latent heat flux to further reduce sensible heat flux and resulted in the second largest cooling of the three regions.

\section{Discussion and conclusions}

\section{a. Impacts of CMIP5 historical land cover change in CCSM4}

The GLM historical land cover change analysis shows that from 1850 to 2005 the time series had increases in crops of $9.8 \times 10^{6} \mathrm{~km}^{2}$, pasture of $25.5 \times 10^{6} \mathrm{~km}^{2}$, and secondary vegetation of $13.7 \times 10^{6} \mathrm{~km}^{2}$, which came from a decrease in primary vegetation of $-49.0 \times$ $10^{6} \mathrm{~km}^{2}$. In the CLM4 land surface parameters, these changes in land units resulted in reductions of tree PFTs by $-5.5 \times 10^{6} \mathrm{~km}^{2}$, of grass PFTs by $-3.3 \times 10^{6} \mathrm{~km}^{2}$, and of shrub PFTs by $-1.0 \times 10^{6} \mathrm{~km}^{2}$. The GLM historical harvest area of $47.4 \times 10^{6} \mathrm{~km}^{2}$ also resulted in an additional $18.5 \times 10^{6} \mathrm{~km}^{2}$ of tree PFTs being harvested through the period.

When the CLM4 parameters were prescribed in the CCSM4 full transient historical simulation, the model produced a land use flux of $0.76 \mathrm{PgC}^{-1}$, resulting in a cumulative total of $119.3 \mathrm{PgC}$ over the period. The change in ecosystem carbon over the period was -64.5 $\mathrm{PgC}$, giving an effective land sink of $54.8 \mathrm{PgC}$. The land use flux combined with an increase in the product pools of $8.4 \mathrm{PgC}$ to give a total land use flux out of the land ecosystem of $127.7 \mathrm{PgC}$. This compares with the higher bookkeeping estimates of land use flux of $156.0 \mathrm{PgC}$ from 1850 to 2000 by Houghton (2003) and of $157.5 \mathrm{PgC}$ from 1850 to 2006 by Canadell et al. (2007).

The CCSM4 historical simulation had a global annualaveraged wood harvest carbon flux of $0.41 \mathrm{PgC}^{-1}$, resulting in a cumulative wood harvest total of 64.0 PgC. This value was substantially lower than the total GLM wood harvest carbon flux of 101.5 PgC. The time series analysis shows that this was due to low wood harvest in CLM4-CN for the entire period. At the start of the historical period in 1850 the CLM4-CN model simulated

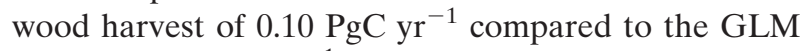
value of $0.23 \mathrm{PgC} \mathrm{yr}^{-1}$. By the end of the historical period the 2005 wood harvest flux was still lower in CLM4-

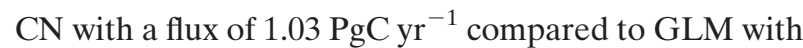
1.26 $\mathrm{PgC} \mathrm{yr}^{-1}$. These differences are similar to differences in the historical wood harvest simulated by Shevliakova et al. (2009), which start in 1850 at around $0.2 \mathrm{PgC} \mathrm{yr}^{-1}$ and end in 2005 at $1.2 \mathrm{PgC} \mathrm{yr}^{-1}$.

Comparison with the 1959 to 2006 land use flux estimates of Canadell et al. (2007) show that CLM4-CN produced reasonable land use change fluxes of 1.34 $\mathrm{PgC} \mathrm{yr}^{-1}$ over the period compared to the bookkeeping estimate of $1.5 \mathrm{PgC} \mathrm{yr}^{-1}$. Further analysis, however, shows that CLM4-CN produces a substantially smaller land sink (NPP - heterotropic respiration - fire) over the period of 1.01 compared to the $1.9 \mathrm{PgC} \mathrm{yr}^{-1}$ bookkeeping estimate. The impact of this smaller land sink was a positive net ecosystem exchange of $0.32 \mathrm{PgC} \mathrm{yr}^{-1}$ to the atmosphere in CCSM4 compared to a negative

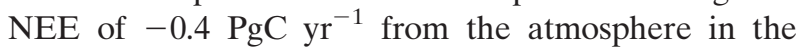
Canadell et al. (2007) estimates.

The primary biogeophysical impact of historical land cover change on the CCSM4 land surface climate was increased global annual-averaged land surface albedo, resulting in a global cooling of land near-surface temperature by $0.1{ }^{\circ} \mathrm{C}$. This was the result of reduced absorbed shortwave radiation over land of $-0.3 \mathrm{~W} \mathrm{~m}^{-2}$ that produced nearly equal reductions in outgoing longwave radiation, sensible heat flux, and latent heat flux. The land cover change and wood harvest prescription also reduced global annual-averaged LAI by -0.04 over the period.

When combined with the other historical transient forcings, the global annual-averaged land surface albedo changes were overwhelmed by decreases in snow albedo through black carbon on snow and reduced snow cover through high-latitude warming. The global annualaveraged LAI also responded more strongly to increased atmospheric $\mathrm{CO}_{2}$, nitrogen deposition and extended high-latitude growing seasons, with an increase of 0.11 despite the prescription of human land cover change and wood harvest through the period.

The CCSM4 full transient global changes in land shortwave and longwave radiation fluxes also were more strongly impacted by increases in aerosol burden and $\mathrm{CO}_{2}$ concentration than through changes in surface properties due to land cover change. Despite the decrease in land surface albedo, the decrease in global annualaveraged land-absorbed shortwave was nearly five times larger in the full transient simulation at $-1.4 \mathrm{~W} \mathrm{~m}^{-2}$ than in the land-cover-change-only simulation. The decrease in outgoing longwave radiation, however, was larger than the decrease in shortwave radiation absorbed with the net result an increase in global annual-averaged land surface radiation budget and warming of global annualaveraged land near-surface temperatures by $0.98^{\circ} \mathrm{C}$.

At a regional level the land cover change impacts were present in both simulations. In all of the land cover 
change regions analyzed land surface albedo increased, with cooling in the land-cover-change-only experiment and reduced warming in the full transient experiment. The largest impacts in both experiments were in eastern North America with near-surface annual average cooling in the land-cover-change-only experiment of $-0.45^{\circ} \mathrm{C}$, corresponding with the largest reduction in near-surface warming in the full transient experiment.

\section{b. Impacts of CMIP5 RCP land cover change in CCSM4}

The RCP 2.6 GLM land cover corresponded with the lowest radiative pathway but had the largest increase in crops of all the RCPs at $5.3 \times 10^{6} \mathrm{~km}^{2}$. Much of the large increase in crops in this RCP was the result of implementing biofuels as crops, often at the expense of primary and secondary forests. The RCP had the second largest decrease in primary vegetation at $-15.3 \times$ $10^{6} \mathrm{~km}^{2}$ and the smallest increase in secondary vegetation at $10.7 \times 10^{6} \mathrm{~km}^{2}$. In the CLM4 parameters these land unit changes were realized through nearly equal losses of tree PFTs at $-2.7 \times 10^{6} \mathrm{~km}^{2}$ and grass PFTs at $-2.1 \times 10^{6} \mathrm{~km}^{2}$ and through a smaller decrease in shrubs of $-0.4 \times 10^{6} \mathrm{~km}^{2}$. The cumulative GLM wood harvest area of $140.7 \times 10^{6} \mathrm{~km}^{2}$ was the lowest of the RCPs; however, in the CLM4 parameters the tree PFT harvest area of $88.2 \times 10^{6} \mathrm{~km}^{2}$ was the second highest of the RCPs due to higher tree PFT density in the RCP.

The CCSM4 RCP 2.6 simulation had the lowest global wood harvest flux of all of the RCPs at $1.43 \mathrm{PgC} \mathrm{yr}^{-1}$ and the second lowest land use flux at $1.84 \mathrm{PgC} \mathrm{yr}^{-1}$. While these values were more than double the historical values, RCP 2.6 had half of the historical NEE at $0.18 \mathrm{PgC} \mathrm{yr}^{-1}$, with a much smaller loss in ecosystem carbon at $-24.5 \mathrm{PgC}$ and a smaller release of carbon to the atmosphere at $15.4 \mathrm{PgC}$. As found in the historical period, the CCSM4 RCP 2.6 cumulative wood harvest flux of $136.2 \mathrm{PgC}$ was substantially lower than the GLM wood harvest carbon of $164.6 \mathrm{PgC}$.

The RCP 4.5 GLM land cover corresponded with the lower midrange radiative pathway and had the only decrease in crops of all the RCPs at $-4.2 \times 10^{6} \mathrm{~km}^{2}$. This combined with a similar size decrease in pasture at $-4.7 \times 10^{6} \mathrm{~km}^{2}$ to produce the largest increase in secondary vegetation of the RCPs at $20.7 \times 10^{6} \mathrm{~km}^{2}$. Much of the conversion from crop land and pasture to secondary vegetation in RCP 4.5 was for the expansion of forests for carbon storage, reflecting the use of land management for carbon mitigation in the RCP. In the CLM4 parameters these changes were mainly realized through increases in tree PFTs of $3.0 \times 10^{6} \mathrm{~km}^{2}$, with smaller increases in grass PFTs of $1.0 \times 10^{6} \mathrm{~km}^{2}$ and shrub PFTs of $0.2 \times 10^{6} \mathrm{~km}^{2}$. The cumulative GLM wood harvest area of $218.9 \times 10^{6} \mathrm{~km}^{2}$ was the highest of all RCPs, but in CLM4 parameters it had the lowest tree PFT harvest area of the RCPs at $69.0 \times 10^{6} \mathrm{~km}^{2}$. This reflected the very low tree densities found in nonforest wood harvest, which made up much of the GLM wood harvest area.

The CCSM4 RCP 4.5 simulation had the largest magnitude negative NEE flux of the RCPs at $-0.69 \mathrm{PgC} \mathrm{yr}^{-1}$, resulting in an increase in ecosystem carbon of $61.0 \mathrm{PgC}$. The increase in ecosystem carbon combined with the increase in product pool carbon of $6.3 \mathrm{PgC}$ to result in a removal of $67.3 \mathrm{PgC}$ from the atmosphere. The RCP 4.5 simulation had the lowest land use flux of the RCPs at $1.56 \mathrm{PgC} \mathrm{yr}^{-1}$, which produced a cumulative flux of 148.0 PgC over the period. The wood harvest flux of $1.52{\mathrm{PgC} \mathrm{yr}^{-1}}^{-1}$ resulted in a cumulative wood harvest of 144.6 PgC, again smaller than the GLM wood harvest carbon of $179.6 \mathrm{PgC}$ for the RCP.

The RCP 6.0 GLM land cover corresponded with the higher midrange radiative pathway and had the largest decrease in pasture at $-14.4 \times 10^{6} \mathrm{~km}^{2}$ with the largest increase in secondary vegetation at $23.6 \times$ $10^{6} \mathrm{~km}^{2}$. The RCP also had the second largest increase in crops at $3.7 \times 10^{6} \mathrm{~km}^{2}$ and the smallest decrease in primary vegetation at $-11.9 \times 10^{6} \mathrm{~km}^{2}$. In the CLM4 parameters RCP 6.0 had the largest decrease in grass of all the RCPs at $-3.0 \times 10^{6} \mathrm{~km}^{2}$, reflecting the large reduction in pasture, with smaller decreases in tree and shrub PFTs of $-0.3 \times 10^{6} \mathrm{~km}^{2}$, reflecting the intension of keeping forest areas constant. The cumulative GLM wood harvest area of $155.0 \times 10^{6} \mathrm{~km}^{2}$ was the second lowest of the RCPs, which was true in the CLM4 tree PFT harvest area as well at $88.2 \times 10^{6} \mathrm{~km}^{2}$.

The CCSM4 RCP 6.0 simulation was the only other $\mathrm{RCP}$ to have a negative NEE flux at $-0.35 \mathrm{PgC} \mathrm{yr}^{-1}$. The negative NEE resulted in a cumulative increase in ecosystem carbon of $26.1 \mathrm{PgC}$, which was less than half the value of the RCP 4.5 simulation. The increase in ecosystem carbon combined with an increase in the product pool of $8.9 \mathrm{PgC}$ to remove $35.0 \mathrm{PgC}$ from the atmosphere of the simulation. The RCP had a land use flux of 1.90 $\mathrm{PgC} \mathrm{yr}^{-1}$, resulting in a cumulative land use flux of 180.5 $\mathrm{PgC}$ over the period, which was the second highest of the RCPs. The high land use flux was predominantly from the wood harvest flux of $1.65 \mathrm{PgC} \mathrm{yr}^{-1}$, resulting in a cumulative wood harvest of $156.6 \mathrm{PgC}$ over the period. This was the second highest wood harvest amounts of the RCPs, but again this was substantially less than the cumulative GLM wood harvest amount of $185.2 \mathrm{PgC}$.

The RCP 8.5 GLM land cover corresponded with the highest radiative pathway and had the largest decrease in primary vegetation at $-19.0 \times 10^{6} \mathrm{~km}^{2}$. This was 
realized through increases in crops of $2.8 \times 10^{6} \mathrm{~km}^{2}$, pasture of $3.4 \times 10^{6} \mathrm{~km}^{2}$, and secondary vegetation of $12.8 \times 10^{6} \mathrm{~km}^{2}$. This was consistent with the RCP having the largest decline in forests, which was reflected in the CLM4 parameters that had the largest loss of tree PFTs of all RCPs at $3.5 \times 10^{6} \mathrm{~km}^{2}$. The cumulative GLM wood harvest area was the largest of the RCPs at $214.6 \times 10^{6} \mathrm{~km}^{2}$. This also was the case in the CLM4 parameters with a cumulative tree PFT harvest area of $123.2 \times 10^{6} \mathrm{~km}^{2}$, which was one and a half times larger than RCP 2.6 and RCP 6.0 and over six times larger than the historical tree PFT harvest area.

The CCSM4 RCP 8.5 simulation had the highest land use carbon flux of all the RCPs at $2.7 \mathrm{PgC} \mathrm{yr}^{-1}$ with a cumulative land use flux of $256.3 \mathrm{PgC}$. This was over three times the historical land use flux. The RCP 8.5 also had a wood harvest flux of $2.54 \mathrm{PgC} \mathrm{yr}^{-1}$, which was six times the historical value. The cumulative wood harvest flux over the period was $240.9 \mathrm{PgC}$, which was again less than the GLM wood harvest of 253.0 PgC. Despite the high land use and wood harvest carbon fluxes, RCP 8.5 had a positive NEE flux of only $0.38 \mathrm{PgC} \mathrm{yr}^{-1}$ with a cumulative loss of $-49.0 \mathrm{PgC}$ from the land ecosystem and an increase of $18.7 \mathrm{PgC}$ in product pool, resulting in a release of $30.3 \mathrm{PgC}$ into the atmosphere over the period. This meant that, despite the extensive wood harvest and tree loss in the RCP, the carbon lost from the ecosystem and released to the atmosphere was still less than that simulated over the historical period.

The relatively small net impacts of land cover change and climate on the terrestrial ecosystem under the RCP 8.5 land management scenario can be attributed to large increases in gross primary production of $25 \%$ and net primary production of $19 \%$. These increases in primary productivity occurred despite human disturbance, primarily due to the increase in atmospheric $\mathrm{CO}_{2}$ concentration by $145 \%$ and through warming that resulted in longer high-latitude growing seasons and increased nitrogen availability in soils with increased microbial activity. The increases in primary productivity also exceeded increases in heterotrophic respiration under the warmer surface climate.

What the CCSM4 simulations therefore show is that in RCP 8.5, land cover change and wood harvest changed the ability of the terrestrial carbon cycle to store increasing amounts of carbon under higher atmospheric $\mathrm{CO}_{2}$ and warmer surface climate into a situation where carbon currently stored in the ecosystem was released into the atmosphere. The opposite was true in RCP 4.5 in which reforestation was able to store nearly as much carbon in the ecosystem as was lost over the historical period. This was despite the continuing increase in wood harvest over the RCP 4.5 period.
As mentioned in section 2, the RCP 6.0 and RCP 8.5 wood harvest parameters used in the simulations of this paper have been revised from the original CMIP5 wood harvest parameters provided by Hurtt et al. (2011) for the two RCPs. In the official CMIP5 CCSM4 simulations reported in Meehl et al. (2012), however, these two RCPs have CLM4 wood harvest parameters prescribed from the original CMIP5 wood harvest area values. The original wood harvest area for RCP 6.0 is $275.7 \times 10^{6} \mathrm{~km}^{2}$, which is $77 \%$ larger than the area used in this paper. The original wood harvest area for RCP 8.5 is $366.3 \times 10^{6} \mathrm{~km}^{2}$, which is $71 \%$ larger.

The impact of these very high wood harvest areas on the carbon cycle in the CCSM4 simulations was to greatly increase the wood harvest and land use carbon fluxes beyond those expected for the RCPs. For RCP 6.0 the original wood harvest parameters resulted in a wood harvest carbon flux of $3.58 \mathrm{PgC} \mathrm{yr}^{-1}$ with a cumulative wood harvest of $339.6 \mathrm{PgC}$. This was over twice the CCSM4 result with the revised wood harvest parameters and nearly twice the global wood harvest modeled for the RCP by the AIM team (Fujino et al. 2006). For RCP 8.5 the original wood harvest parameters resulted in a wood harvest carbon flux of $4.84 \mathrm{PgC} \mathrm{yr}^{-1}$ with a cumulative wood harvest of $459.8 \mathrm{PgC}$. This also was nearly twice the CCSM4 result, with the revised wood harvest parameters and the global wood harvest modeled for the RCP by the MESSAGE team (Riahi et al. 2007).

\section{c. Conclusions and implications}

We have developed new time series of transient CLM4 PFT and tree PFT wood harvest parameters that capture the nature of CMIP5 land cover change and wood harvest trajectories for the historical period from 1850 to 2005 and for the four RCP scenarios from 2006 to 2100. The CLM4 transient parameters have been used to represent human land use and land cover change in CCSM4 fully coupled transient climate simulations for each of these periods. Analysis of the historical and RCP transient CLM4 parameters show that our methods are faithful in maintaining the CMIP5 narrative while being consistent with current day MODIS-derived PFT and bioclimatically modeled potential vegetation PFT distributions.

Analysis of the biogeochemical impacts of historical land cover change in CCSM4 found that the model had a cumulative land use flux of $127.7 \mathrm{PgC}$ from 1850 to 2005 , lower than but consistent with global estimates by Houghton (2003) and Canadell et al. (2007) of around $156 \mathrm{PgC}$ for the same period. Further analysis from 1959 to 2005 found that, while CCSM4 produced good land use fluxes, it simulated a relatively weak terrestrial 
biosphere sink that resulted in a positive NEE flux of $0.32 \mathrm{PgC} \mathrm{yr}^{-1}$, which is opposite to the negative NEE flux of $-0.4 \mathrm{PgC} \mathrm{yr}^{-1}$ reported by Canadell et al. (2007) for the period.

The biogeophysical impacts of transient land cover change alone in CCSM4 were found to be global annualaveraged near-surface atmospheric cooling over land of $-0.1^{\circ} \mathrm{C}$. This was directly through increased surface albedo and reduced shortwave radiation absorption, which resulted in equal decreases in outgoing longwave radiation, sensible heat flux, and latent heat flux from the land. The land cover change also resulted in a global annualaveraged decrease in LAI of -0.04 in the CLM-CN model. The climate impacts were largest in eastern North America, which had cooling of $-0.45^{\circ} \mathrm{C}$, and in other areas where vegetation and snow interactions were greatest.

When combined with other transient climate forcings, the higher albedo from land cover change was overwhelmed at global scales by decreases in snow albedo from black carbon deposition and from high-latitude warming. At regional scales, however, the land cover change forcing reduced warming, with the biggest impacts again in eastern North America. The full transient simulation also showed that CLM-CN had a global annual average increase in LAI of 0.11 , with the impact of increased atmospheric $\mathrm{CO}_{2}$, nitrogen deposition, and lengthened growing season having a larger influence than human land cover change and wood harvest.

The RCP simulations showed that the CLM4 transient PFT and tree PFT wood harvest parameters can be used to represent a wide range of human land use and land cover change scenarios in CCSM4. In the reforestation scenario of RCP 4.5, CCSM4 simulated a drawdown 67.3 PgC from the atmosphere into the terrestrial ecosystem and product pools. This was close to the amount of carbon lost to the atmosphere over the historical period. By contrast, the RCP 8.5 scenario, where land management is used meet resource requirements rather than address carbon mitigation, deforestation and high wood harvest undermine the ability of the terrestrial biosphere to store increasing amounts of carbon under higher atmospheric $\mathrm{CO}_{2}$ and warmer surface climate, with $30.3 \mathrm{PgC}$ currently stored in the ecosystem released into the atmosphere.

Acknowledgments. This work was supported by the Community Climate System Model (CCSM) Land and Biogeochemistry Working Groups, and the Weather and Climate Impact Assessment Science Initiative, which are all sponsored by the National Science Foundation. Thanks also are due to the software engineers and scientists who worked on developing CCSM4 and to the Computational and Information Systems Laboratory at NCAR, which provided the computing resources through the Climate Simulation Laboratory. This study also was supported by the U.S. Department of Energy, Office of Science, Biological and Environmental Research. Oak Ridge National Laboratory is managed by UT-Battelle, LLC for the U.S. Department of Energy under Contract DEAC05-00OR22725. This work also was supported by the National Science Foundation Grants ATM-0107404 and ATM-0413540, and the University of Kansas, Center for Research. GLM transient land cover change and wood harvest data were provided by the CMIP5 land use harmonization team of George Hurtt, Louise Parsons Chini, and Steve Frolking. MODIS land surface products were provided by the MODIS Land Science Team. Historical cropping and potential vegetation data were provided by the Center for Sustainability and the Global Environment at the University of Wisconsin and by Navin Ramankutty at McGill University.

\section{REFERENCES}

Bala, G., K. Caldeira, M. Wickett, T. J. Phillips, D. B. Lobell, C. Delire, and A. Mirin, 2007: Combined climate and carboncycle effects of large-scale deforestation. Proc. Natl. Acad. Sci. USA, 104, 6550-6555.

Betts, R. A., P. D. Falloon, K. K. Goldewijk, and N. Ramankutty, 2001: Biogeophysical effects of land use on climate: Model simulations of radiative forcing and large-scale temperature change. Agric. For. Meteor., 142, 216-233.

Bonan, G. B., 2008: Forests and climate change: Forcings, feedbacks, and the climate benefits of forests. Science, 320, 14441449, doi:10.1126/science.1155121.

Canadell, J. G., and Coauthors, 2007: Contributions to accelerating atmospheric $\mathrm{CO}_{2}$ growth from economic activity, carbon intensity, and efficiency of natural sinks. Proc. Natl. Acad. Sci. USA, 104, 18 866-18 870.

Feddema, J. J., K. W. Oleson, G. B. Bonan, L. O. Mearns, L. E. Buja, G. A. Meehl, and W. M. Washington, 2005: The importance of land-cover change in simulating future climates. Science, 310, 1674-1678.

Findell, K. L., E. Shevliakova, P. C. D. Milly, and R. J. Stouffer, 2007: Modeled impact of anthropogenic land cover change on climate. J. Climate, 20, 3621-3634.

Fujino, J., R. Nair, M. Kainuma, T. Masui, and Y. Matsuoka, 2006: Multi-gas mitigation analysis on stabilization scenarios using AIM global model. Energy J., 3, 343-354.

Gent, P. R., and Coauthors, 2011: The Community Climate System Model version 4. J. Climate, 24, 4973-4991.

Houghton, R. A., 2003: Revised estimates of the annual net flux of carbon to the atmosphere from changes in land use and land management 1850-2000. Tellus, 55, 378-390 doi:10.1034/j.16000889.2003.01450.x.

Hurtt, G. C., S. Frolking, M. G. Fearon, B. Moore, E. Shevliakova, S. Malyshev, S. W. Pacala, and R. A. Houghton, 2006: The underpinnings of land-use history: Three centuries of global gridded land-use transitions, wood harvest activity, and resulting secondary lands. Global Change Biol., 12, 12081229. 
and Coauthors, 2011: Harmonization of land-use scenarios for the period 1500-2100: 600 years of global gridded annual land-use transitions, wood harvest, and resulting secondary lands. Climatic Change, 109, 117-161, doi:10.1007/s10584-011-0153-2.

Lawrence, D. M., K. W. Oleson, M. G. Flanner, C. G. Fletcher, P. J. Lawrence, S. Levis, S. C. Swenson, and G. B. Bonan, 2012: The CCSM4 land simulation, 1850-2005: Assessment of surface climate and new capabilities. J. Climate, 25, 2240-2260.

Lawrence, P. J., and T. N. Chase, 2007: Representing a new MODIS consistent land surface in the Community Land Model (CLM 3.0). J. Geophys. Res., 112, G01023, doi:10.1029/ 2006JG000168.

— , and - 2010: Investigating the climate impacts of global land cover change in the Community Climate System Model. Int. J. Climatol., 30, 2066-2087, doi:10.1002/joc.2061.

Meehl, G. A., and Coauthors, 2012: Climate system response to external forcings and climate change projections in CCSM4 J. Climate, in press.

Oleson, K. W., and Coauthors, 2010: Technical description of version 4.0 of the Community Land Model (CLM). NCAR Tech. Note NCAR/TN-478+STR, 257 pp.
Riahi, K., A. Gruebler, and N. Nakićenović, 2007: Scenarios of long-term socio-economic and environmental development under climate stabilization. Technol. Forecasting Soc. Change, 74, 887-935.

Shevliakova, E., and Coauthors, 2009: Carbon cycling under 300 years of land use change: Importance of the secondary vegetation sink. Global Biogeochem. Cycles, 23, GB2022, doi:10.1029/ 2007GB003176.

Taylor, K. E., R. J. Stouffer, and G. A. Meehl, 2009: A summary of the CMIP5 experiment design. PCMDI Rep., 32 pp.

van Vuuren, D. P., M. G. J. den Elzen, P. L. Lucas, B. Eickhout, B. J. Strengers, B. van Ruijven, S. Wonink, and R. van Houdt, 2007: Stabilizing greenhouse gas concentrations at low levels: An assessment of reduction strategies and costs. Climatic Change, 81, 119-159, doi:10.1007/s10584-006-9172-9.

—, and Coauthors, 2011: The representative concentration pathways: An overview. Climatic Change, 109, 5-31, doi:10.1007/ s10584-011-0148-z.

Wise, M. A., and Coauthors, 2009: Implications of limiting $\mathrm{CO}_{2}$ concentrations for land use and energy. Science, 324, 11831186. 